\title{
State-Dependent Function of Neocortical Chandelier Cells
}

\author{
Alan R. Woodruff, ${ }^{1}$ Laura M. McGarry, ${ }^{1}$ Tim P. Vogels, ${ }^{1}$ Melis Inan, ${ }^{2}$ Stewart A. Anderson, ${ }^{2}$ and Rafael Yuste ${ }^{1}$ \\ ${ }^{1}$ Department Biological Sciences, Howard Hughes Medical Institute, Columbia University, New York, New York 10027, and ${ }^{2}$ Department of Psychiatry, \\ Weill Cornell Medical College, Cornell University, New York, New York 10065
}

Chandelier (axoaxonic) cells (ChCs) are a distinct group of GABAergic interneurons that innervate the axon initial segments of pyramidal cells. However, their circuit role and the function of their clearly defined anatomical specificity remain unclear. Recent work has demonstrated that chandelier cells can produce depolarizing GABAergic PSPs, occasionally driving postsynaptic targets to spike. On the other hand, other work suggests that ChCs are hyperpolarizing and may have an inhibitory role. These disparate functional effects may reflect heterogeneity among ChCs. Here, using brain slices from transgenic mouse strains, we first demonstrate that, across different neocortical areas and genetic backgrounds, upper Layer $2 / 3 \mathrm{ChCs}$ belong to a single electrophysiologically and morphologically defined population, extensively sampling Layer 1 inputs with asymmetric dendrites. Consistent with being a single cell type, we find electrical coupling between ChCs. We then investigate the effect of chandelier cell activation on pyramidal neuron spiking in several conditions, ranging from the resting membrane potential to stimuli designed to approximate in vivo membrane potential dynamics. We find that under quiescent conditions, chandelier cells are capable of both promoting and inhibiting spike generation, depending on the postsynaptic membrane potential. However, during in vivo-like membrane potential fluctuations, the dominant postsynaptic effect was a strong inhibition. Thus, neocortical chandelier cells, even from within a homogeneous population, appear to play a dual role in the circuit, helping to activate quiescent pyramidal neurons, while at the same time inhibiting active ones.

\section{Introduction}

In the early postnatal brain, the GABAergic system has a wellestablished excitatory role made possible by the relative expression levels of two transmembrane chloride transporters, KCC2 and NKCC1 (Ben-Ari, 2002). By adulthood, the balance of these transporters has been inverted in pyramidal neurons, resulting in a hyperpolarizing shift in $E_{\mathrm{Cl}-}$ and consequently $E_{\mathrm{GABA}}$ (Rivera et al., 1999; Yamada et al., 2004; Romo-Parra et al., 2008), and leading to the hyperpolarizing inhibition that is characteristic of GABAergic interneurons. However, some reports show excitatory GABAergic effects in mature neurons (Alger and Nicoll, 1982; Staley et al., 1995; Chavas and Marty, 2003; Gulledge and Stuart, 2003; Choi et al., 2008; Viitanen et al., 2010). While some of these excitatory effects result from intense, prolonged $\mathrm{GABA}_{\mathrm{A}}$ receptor activation and a breakdown in the $\mathrm{Cl}^{-}$gradient, and may occur predominantly under pathological conditions (Cohen et al., 2002), others rely simply on $\mathrm{GABA}_{\mathrm{A}}$ reversal lying between the resting membrane potential and spike threshold.

Chandelier cells, also known as axoaxonic cells, are a particularly distinctive interneuronal type characterized by their axonal morphology, with arrays of boutons - termed cartridges - that resemble the candlesticks of a chandelier (Jones, 1975; Szen-

Received July 29, 2011; revised Oct. 13, 2011; accepted Oct. 14, 2011.

Author contributions: A.R.W., T.P.V., and R.Y. designed research; A.R.W., L.M.M., and M.I. performed research; S.A.A. contributed unpublished reagents/analytic tools; A.R.W. and L.M.M. analyzed data; A.R.W., L.M.M., and R.Y. wrote the paper.

This work was supported by the Kavli Institute for Brain Science and the National Eye Institute. We thankJ. Miller, Y. Shin, and L. Gibson for anatomical reconstructions and members of the laboratory for help and comments.

Correspondence should be addressed to Alan Woodruff, Department of Biological Sciences, Columbia University, Box 4822, 550 West 120 Street, New York, NY 10027. E-mail: woodruff@hifo.uzh.ch.

DOI:10.1523/JNEUROSCI.3894-11.2011

Copyright $\odot 2011$ the authors $\quad 0270-6474 / 11 / 3117872-15 \$ 15.00 / 0$ tagothai, 1975; Somogyi, 1977; Howard et al., 2005). These cartridges are apposed to the axon initial segment of pyramidal neurons (Somogyi, 1977; Fairen and Valverde, 1980), suggesting a critical role for ChCs in controlling the output of their postsynaptic targets. Being GABAergic, ChCs were expected to provide a strong inhibition of action potential (AP) output, but recent work has suggested a more complicated picture, with the axonal $\mathrm{GABA}_{\mathrm{A}}$ reversal potential $\left(E_{\mathrm{GABA}}\right)$ depolarized relative to rest and to other neuronal compartments (Szabadics et al., 2006; Khirug et al., 2008; Woodruff et al., 2009). This suggests that cortical chandelier cells may provide GABAergic excitation, in addition to the expected inhibition. At the same time, in CA1 hippocampus, ChCs appear to be mostly hyperpolarizing (Glickfeld et al., 2009), the exception being a direct suprathreshold excitation that has also been described in cortex (Szabadics et al., 2006; Molnar et al., 2008) and amygdala (Woodruff et al., 2006). This functional difference may be due to the different brain structures within which the ChCs reside. Alternatively, differences in ChC function may be due to their heterogeneity (DeFelipe et al., 1985; Inda et al., 2009), with different studies sampling different $\mathrm{ChC}$ subtypes.

Here we re-examine the function of the ChCs and their potential heterogeneity using ChCs identified in two types of transgenic mice. We first explore the morphological and electrophysiological diversity of upper-layer neocortical ChCs, demonstrating that they form a homogeneous population. We then test the ability of cortical ChCs to provide subthreshold excitatory input to pyramidal neurons under a variety of conditions, ranging from the resting state observed in in vitro slices to a scenario designed to approximate membrane potential dynamics in the awake animal. We demonstrate a capacity for ChCs to both 
promote and inhibit spike generation in pyramidal neurons during quiescent conditions. However, under conditions simulating high network activity, the dominant effect is inhibition.

\section{Materials and Methods}

Slice preparation and electrophysiological recordings. Animal handling and experimentation was performed according to NIH and local Institutional Animal Care and Use Committee guidelines. G42 (Chattopadhyaya et al., 2004) and Nkx2.1 mice (Woodruff et al., 2009) of either sex were quickly decapitated, and $300 \mu \mathrm{m}$ coronal slices were prepared using a Leica VT1000-S vibratome. Animals used for the cluster analysis of morphological and physiological properties ranged in age from postnatal day 16 (P16) to P25. Except for the cells shown in Figure 2, $D$ and $E$, those used for the remainder of this paper (including the dendrite analysis in Fig. 2) were from animals aged $\mathrm{P} 18-\mathrm{P} 25$. The cutting solution contained the following (in mM): $27 \mathrm{NaHCO}_{3}, 1.5 \mathrm{NaH}_{2} \mathrm{PO}_{4}, 222$ sucrose, $2.6 \mathrm{KCl}, 3.5$ $\mathrm{MgSO}_{4}$, and $0.5 \mathrm{CaCl}_{2}$. Slices were incubated for $30 \mathrm{~min}$ at $32^{\circ} \mathrm{C}$ in an oxygenated $\left(95 \% \mathrm{O}_{2}\right.$ and $\left.5 \% \mathrm{CO}_{2}\right)$ artificial CSF (ACSF), pH 7.4, solution containing the following (in $\mathrm{mM}$ ): $126 \mathrm{NaCl}, 3 \mathrm{KCl}, 3 \mathrm{MgSO}_{4}, 1$ $\mathrm{CaCl}_{2}, 1.1 \mathrm{NaH}_{2} \mathrm{PO}_{4}, 26 \mathrm{NaHCO}_{3}$, and 10 dextrose. Slices were allowed to equilibrate for at least an additional $30 \mathrm{~min}$ at room temperature before being transferred to the recording chamber. The ACSF used for recording contained the following (in $\mathrm{mm}$ ): $126 \mathrm{NaCl}, 3 \mathrm{KCl}, 1.5 \mathrm{MgSO}_{4}$, $2.5 \mathrm{CaCl}_{2}, 1.1 \mathrm{NaH}_{2} \mathrm{PO}_{4}, 26 \mathrm{NaHCO}_{3}$, and 10 dextrose. Recordings were performed at $34-36^{\circ} \mathrm{C}$ using Multiclamp $700 \mathrm{~B}$ amplifiers (Molecular Devices). Whole-cell pipettes contained a solution including the following (in mM): $127 \mathrm{~K}$-methylsulfate, $8 \mathrm{NaCl}, 8 \mathrm{KCl}, 10 \mathrm{HEPES}, 2 \mathrm{MgATP}$, $0.3 \mathrm{NaGTP}$, and 7 phosphocreatine, adjusted to $\mathrm{pH} 7.3$ with $1 \mathrm{M} \mathrm{KOH}$. Both Nkx2.1 and G42 mice were used for the experiments pertaining to cluster analysis of electrophysiological and morphological variables. All other experiments were performed solely on G42 mice.

Gramicidin perforated patch recordings were performed as described previously (Woodruff et al., 2009). Briefly, recording pipettes (3-5 M $\Omega$ ) were filled with a solution containing the following (in mM): $140 \mathrm{KCl}, 10$ $\mathrm{NaCl}, 10 \mathrm{HEPES}$, and $20-25 \mu \mathrm{g} / \mathrm{ml}$ gramicidin (Sigma-Aldrich), adjusted to $\mathrm{pH} 7.3$ with $1 \mathrm{~m} \mathrm{KOH}$. Gramicidin was prepared as a stock solution at $5 \mathrm{mg} / \mathrm{ml}$ and sonicated before being diluted into the pipette solution. The same solution, without gramicidin, was used to tip-fill pipettes. Both solutions were kept on ice for the duration of experiments. Following formation of a gigaseal, perforation was assessed by continuously presenting $10 \mathrm{mV}$ test pulses to a cell voltage-clamped at $-70 \mathrm{mV}$ while recording series resistance. Recordings began once this value was below $80 \mathrm{M} \Omega$ (all data presented from cells with $R_{\text {series }} 40-80 \mathrm{M} \Omega$ ).

$\mathrm{GABA}_{\mathrm{A}}$ reversal potential was measured in current clamp for gramicidin recordings, manipulating the holding potential of the pyramidal neuron by current injection through the patch pipette. For whole-cell measurements of $E_{\mathrm{GABA}}$, pyramidal neurons were voltage clamped between -40 and $-80 \mathrm{mV}$, in $10 \mathrm{mV}$ increments. Series resistance was monitored throughout the experiment, and cells were discarded if this value changed significantly. All measurements of $E_{\mathrm{GABA}}$ were taken from the soma. For the Layer 1 (L1) stimulation experiments, we used an arbitrary cutoff value of $60 \mathrm{mV}$ to represent the $100 \%$ spiking probability of a pyramidal neuron. For recordings at stimulus intensities lower than that required to generate spikes with $100 \%$ reliability, traces with spikes were digitally removed, and the remaining traces were averaged to calculate the peak EPSP.

Comparing $V_{m}$ values for different internal solutions. Whole-cell membrane potential values have not been corrected for liquid junction potential (LJP), to facilitate comparison with values obtained in previous studies using whole-cell recordings in vivo, in which junction potential (typically with K-gluconate) (Crochet and Petersen, 2006; Poulet and Petersen, 2008; Constantinople and Bruno, 2011) is not corrected for. Membrane potential values obtained using gramicidin recordings have been corrected for the calculated LJP of the gramicidin internal $(+3.0$ $\mathrm{mV}$ ), for the donnan potential ( $-6.2 \mathrm{mV}$, Woodruff et al., 2009) formed across the cell membrane due to chloride impermeability (Kim and Trussell, 2007), and additionally for the LJP of the $\mathrm{KMeSO}_{4}$ solution we used in whole-cell recordings $(+8.36 \mathrm{mV})$. The values given for membrane potential throughout the paper are therefore equivalent for the two recording techniques and represent the value that is or would be recorded using our $\mathrm{KMeSO}_{4}$ internal solution. Based on the difference in calculated LJP between our $\mathrm{KMeSO}_{4}$ and reported $\mathrm{K}$-gluconate solutions, our $V_{\mathrm{m}}$ values are likely $\sim 7 \mathrm{mV}$ more hyperpolarized than the equivalent values reported for in vivo K-gluconate recordings.

Biocytin histochemistry, cell reconstruction, and morphological analysis. At the end of an experiment, slices were fixed and kept overnight in $4 \%$ paraformaldehyde in $0.1 \mathrm{M}$ phosphate buffer $(\mathrm{PB})$ at $4^{\circ} \mathrm{C}$. Slices were then rinsed three times, for $5 \mathrm{~min}$ per rinse, on a shaker in $0.1 \mathrm{M} \mathrm{PB}$. They were then placed in $30 \%$ sucrose mixture (30 g sucrose dissolved in $50 \mathrm{ml}$ $\mathrm{ddH}_{2} 0$ and $50 \mathrm{ml} 0.24 \mathrm{M} \mathrm{PB}$ ) for $2 \mathrm{~h}$ and frozen on dry ice in tissuefreezing medium. Following this, slices were kept overnight in a $-80^{\circ} \mathrm{C}$ freezer. The slices were defrosted, and the tissue freezing medium was removed with three 20 min rinses in $0.1 \mathrm{M} \mathrm{PB}$ while on a shaker. Slices were kept in $1 \%$ hydrogen peroxide in $0.1 \mathrm{M} \mathrm{PB}$ for $30 \mathrm{~min}$ on the shaker to pretreat the tissue, and were then rinsed twice in $0.02 \mathrm{M}$ potassium phosphate saline (KPBS) for $20 \mathrm{~min}$ on the shaker. The slices were then kept overnight on the shaker in avidin-biotin-peroxidase complex. Slices were rinsed three times in $0.02 \mathrm{M}$ KPBS for $20 \mathrm{~min}$ each on the shaker. Each slice was then placed in DAB $\left(0.7 \mathrm{mg} / \mathrm{ml} \mathrm{3,3^{ \prime \prime } -}\right.$ diaminobenzidine, $0.2 \mathrm{mg} / \mathrm{ml}$ urea hydrogen peroxide, $0.06 \mathrm{M}$ Tris buffer in $0.02 \mathrm{M}$ KPBS) until the slice turned light brown, then immediately transferred to $0.02 \mathrm{M} \mathrm{KPBS}$, and finally transferred again to fresh $0.02 \mathrm{~m}$ KPBS after a few minutes. The stained slices were rinsed a final time in $0.02 \mathrm{M} \mathrm{KPBS}$ for $20 \mathrm{~min}$ on a shaker. Each slice was observed under a light microscope and then mounted onto a slide using crystal mount.

Successfully filled and stained neurons were then reconstructed using Neurolucida software (MicroBrightField). The neurons were viewed with a $100 \times$ oil objective on an Olympus IX71 inverted light microscope or an Olympus BX51 upright light microscope. The Neurolucida program projected the microscope image onto a computer drawing tablet. The neuron's processes were traced manually while the program recorded the coordinates of the tracing to create a digital, threedimensional reconstruction. Dendrite polar plots were computed with 20 bins $\left(18^{\circ}\right.$ per bin). The total dendritic length per bin was calculated using Neurolucida Explorer for each neuron, and the length per bin was averaged across all ChCs or basket cells (BCs) to create the polar plots. Statistical analysis was performed in GraphPad InStat.

Cluster analysis. Morphological and physiological properties of chandelier cells were quantitatively characterized by 67 morphological variables describing the soma, dendrites, axons, and cell location, and by 20 physiological parameters describing both passive membrane and firing properties. For the purposes of cluster analysis, we used data from both G42 and Nkx2.1 mice (Woodruff et al., 2009) and found no effect of genotype on the morphological and physiological properties of ChCs. Although the neurons reconstructed for morphological cluster analysis were different from the ones used for the functional study, since both subsets of neurons were drawn from the same population of GFP labeled cells, we have no reason to believe that they could represent different subtypes of ChCs.

Cluster analysis was performed after dimensionality reduction using either principal component analysis (PCA) or feature subset selection (FSS) by correlation filter. The principal components (PCs) were calculated in Matlab, and the number of PCs to use for clustering was selected based on the scree test, in which a plot of the eigenvalues in descending order is examined for when the decrease in eigenvalues plateaus (Cattell 1966). FSS by correlation filter was executed with Knime software. The filter works by keeping the variable with the highest number of correlated variables and removing those correlated with it. "Correlated" is defined as having a correlation coefficient greater than or equal to a threshold set by the user, here set to $r=0.8$. This process is repeated until the maximum correlation between variables is less than the selected threshold. We performed unsupervised hierarchical cluster analysis using Clustan software with Euclidean distance squared as the distance metric and Ward's method as the linkage rule. Three statistical tests were performed to determine whether there was a level of clustering with significant $(p<$ 0.05 ) groups. The best-cut test does an analysis of variance on the fusion 
values (distance at which two clusters join) at every level in the dendrogram. The realized deviates, defined as the standardized difference between a fusion value and the mean fusion value, are compared to find significantly large realized deviates that are at least 1.96 SDs from the mean. The upper tail test applies the upper-tailed $t$ test to the fusion values using the $t$ statistic of realized deviate ${ }^{*}(n-1)$ over $n-2$ degrees of freedom. The bootstrap test performs 1000 trials of randomizing the data and performing cluster analysis on the randomized data, and then compares the random trees to the actual tree. The data matrix was randomized by shuffling the values for each column (variable) independently. The random trees were compared to the actual tree by plotting the fusion value versus the number of clusters for the actual data and the distribution of the randomized data with a confidence interval of $1 \mathrm{SD}$ around the mean. Significant departures of the actual fusion values from random, determined by the $t$ statistic, indicate a number of clusters that are statistically significant.

The quality of clustering was also measured with silhouette analysis, which compares within-cluster and between-cluster distances (Rousseeuw, 1987). The silhouette value of a data point $i$ in cluster $\mathrm{A}$ is as follows:

$$
s(i)=\frac{b(i)-a(i)}{\max [a(i), b(i)]},
$$

where $a(i)$ is the average Euclidean distance between $i$ and all other data points in cluster A, $b(i)$ is the smallest average Euclidean distance between $i$ and all data points contained in one cluster. The value of $s(i)$ is between -1 and 1 . The silhouette width of a clustering is defined as the average of $s(i)$ for all data points. Large positive values indicate that the cluster is compact and well separated from other clusters. To determine whether the clustering achieved a significantly better group structure than random, the data was randomized (using the same method as for the bootstrap test above), and then cluster analysis and silhouette analysis were performed on 500 randomized data sets. $S$ (random) is the average of the 500 random silhouette widths.

In vivo-like noise stimulation. In one set of experiments, we aimed to match the membrane voltage characteristics of the prespike depolarization (PSD) reported by Poulet and Petersen (2008) and Gentet et al. (2010). To test the effect of ChC spikes under these conditions, we subjected pyramidal neurons to repeated presentations of a 1-s-long frozen current stimulus and fired the $\mathrm{ChC}$ (through a short current stimulus) at different times before or after an expected pyramidal spike. The noise stimulus for the pyramidal cell was drawn from low pass filtered white noise kernels (time constant, $\tau=5 \mathrm{~ms}$ ). To mimic in vivo dynamics, we selected two sequences that produced prespike depolarizations similar to those reported in vivo and evoked single spikes rather than bursts. To facilitate later analysis, we decreased the amplitude of the stimulus kernel at the beginning and end of the stimulus and faded into/out of the stimulus slowly to avoid spiking during the initial and final $70 \mathrm{~ms}$.

To create an appropriate current signal for each neuron from the stimulus kernel, we adjusted the DC offset and peak-to-peak amplitude (referred to here as "stretch") of the signal to approximate in vivo membrane potential dynamics with mean membrane potentials of approximately $-65 \mathrm{mV}$, minima of approximately $-75 \mathrm{mV}$, and peak-to-peak amplitudes of $\sim 25 \mathrm{mV}$ (excluding spikes). Additionally, we aimed for the occurrence of one to two spikes throughout a single stimulus episode with spike probabilities between $\sim 0.3$ and 0.7 . We intentionally manipulated the maximum negative value of the prespike depolarization to be below $E_{\mathrm{GABA}}$ to allow for depolarization and potential excitation from the presynaptic chandelier cell.

Having found appropriate offset and stretch parameters, the pyramidal neuron was initially subjected to 200 repetitions of the frozen noise stimulus. The resulting peristimulus spike time histograms were used to determine the expected spike times in response to the stimulus sequence.

We then chose appropriate stimulation times for the chandelier cell to fire an action potential at randomly interleaved times $\Delta t=(-40,-20$, or $-5 \mathrm{~ms})$, or $\Delta t=(-30,-15$, or $-5 \mathrm{~ms})$ before the expected pyramidal spike. We additionally interleaved control trials at $\Delta t=+50 \mathrm{~ms}$ after the expected pyramidal spike. We then recorded the spiking response of the pyramidal neuron to $400-800$ presentations of the same frozen current stimulus, but this time with the additional presynaptic $\mathrm{ChC}$ stimulation, corresponding to $100-200$ trials in each of $3+1$ randomly interleaved $\Delta t$ conditions. The randomized order of four $\Delta t$ intervals was chosen to eliminate time-dependent variations in pyramidal neuron spiking. Because of slow drift in the pyramidal neuron membrane potential, small positive and negative offset currents were sometimes applied during recording to prevent the pyramidal cell from firing (or not firing) on every trial. Such currents were applied when more than $\sim 10$ consecutive trials showed the same response (spike or no spike). We reasoned that because $\Delta t$ presentation was randomized, this was not deleterious to the experiment and should not greatly bias our results, and certainly the experimenter would be blind to the direction of any bias.

\section{Results}

We used both Nkx2.1 mice (Woodruff et al., 2009) and the G42 line of bacterial artificial chromosome (BAC) transgenic mice, in which parvalbumin-positive $(\mathrm{PV}+)$ interneurons express EGFP (Chattopadhyaya et al., 2004), to record from chandelier cells in Layer 2/3 (L2/3) of motor and somatosensory cortical slices. In brain slices from G42 mice, in contrast to the $\mathrm{Nkx} 2.1$ mice, the distinctive axonal arborizations of ChCs could not be seen under wide-field illumination, so prepatch knowledge of the neuron's identity as $\mathrm{ChC}$ or $\mathrm{BC}$ was not possible. By restricting our recordings to the top $\sim 30 \mu \mathrm{m}$ of the layer, adjacent to Layer 1 , we nevertheless estimate the probability of a targeted GFP neuron in a G42 animal being a ChC at $\sim 50-70 \%$. Chandelier cells were clearly distinguished from BCs on the basis of their threshold spiking response (Woodruff et al., 2009) (Fig. 2A,D).

\section{Anatomical homogeneity of sampled chandelier cells}

We first explored the morphological and physiological diversity of our studied population of neocortical chandelier cells. For this purpose, we reconstructed the morphology of $23 \mathrm{ChCs}$, and 67 morphological variables (Table 1) describing the soma, dendrites, axon, and location of the cell were extracted from the reconstruction. To determine whether these ChCs belonged to different populations, we first used unsupervised cluster analysis to test for the existence of statistically different subtypes of neurons, based on morphological properties of the recorded ChCs. One of two dimensionality reduction techniques, either PCA or FSS using a correlation filter, was applied before cluster analysis. Three statistical tests were used to determine a significant level $(p<0.05)$ of clustering (see Materials and Methods). For the morphology data set, the correlation filter removed 27 variables, and cluster analysis with the remaining 40 variables had no significant divisions (data not shown). In cluster analysis with PCA, the bootstrap and two-tailed tests also failed to find any significant divisions. Nevertheless, the best-cut test found significance at the three- and two-cluster levels, indicating the potential existence of different subtypes of ChCs (Fig. $1 \mathrm{~A}$, purple, dark orange, light blue clusters, division marked above 6 Euclidean distance squared).

We therefore decided to further investigate the group structure of the three- and two-cluster levels found by cluster analysis with PCA, analyzing the three-cluster level for any further evidence of group structure. The data set was plotted in principal component space to search for separation of clusters. The first three principal components were used for analysis based on the scree test and on their carrying $>60 \%$ of the variance (see Materials and Methods). In all three planes (PC1-PC2, PC1-PC3, and PC2-PC3) and in three-dimensional space, the clusters were not distinct and boundaries of the cluster areas overlapped (Fig. $1 B$ ). We assessed the quality of clustering with silhouette analysis (see 


\begin{tabular}{|c|c|}
\hline 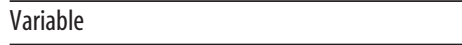 & Description \\
\hline \multicolumn{2}{|l|}{ Variables describing the soma } \\
\hline Somatic perimeter $(\mu \mathrm{m})$ & Perimeter of the soma \\
\hline Somatic area $(\mu \mathrm{m} 2)$ & Area of the soma \\
\hline Somatic aspect ratio & Max. diameter of soma/min. diameter of soma \\
\hline Somatic compactness & {$\left[\left([4 / \pi]^{*}\right.\right.$ area $\left.) 1 / 2\right] /$ max. diameter } \\
\hline Somatic form factor & $\left(4 \pi^{*}\right.$ area $) /($ perimeter 2$)$ \\
\hline Somatic roundness & $(4 *$ area $) /\left(\pi^{*}\right.$ max. diameter 2$)$ \\
\hline \multicolumn{2}{|l|}{ Variables describing the axon } \\
\hline Axonal node total & Total number of axonal nodes (branching points) \\
\hline Total axonal length $(\mu \mathrm{m})$ & Sum of lengths of all axon segments, measured along tracing (not straight line distance) \\
\hline Total surface area of axon $(\mu \mathrm{m} 2)$ & $2 \pi r 2+2 \pi r h$, surface area calculated by modeling axon as a cylinder with diameter defined by thickness of segment in reconstruction \\
\hline Ratio of axonal length to surface area $(1 / \mu \mathrm{m})$ & Total axonal length/total surface area of axon \\
\hline Highest-order axon segment & Maximum number obtained after each segment is numbered by how many nodes it is removed from the initial segment \\
\hline Axonal torsion ratio & $\begin{array}{l}\text { Total axonal length/total axonal length of fan in diagram where the fan in diagram is } 2 D \text { projection of the neuron constructed by compiling } \\
\text { traces swept around a vertical axis; torsion ratio }=1 \text { corresponds to no loss of length; values larger than } 1 \text { correspond to the factor by } \\
\text { which the processes have decreased in the fan in diagram }\end{array}$ \\
\hline K-dim of axon & Fractal dimension of the axon calculated using linear regression and the nested cubes method \\
\hline Axonal polar angle average & $\begin{array}{l}\text { Average of polar angles of all axonal nodes; the polar angle is the angle between the two lines passing through the node and the endpoints } \\
\text { of the next segments }\end{array}$ \\
\hline Axonal polar angle SD & SD of axonal polar angles \\
\hline Axonal local angle average & $\begin{array}{l}\text { Average of local angles of all axonal nodes; the local angle is the angle between the two lines passing through the node and points adjacent } \\
\text { to the node on the two following segments }\end{array}$ \\
\hline Axonal local angle SD & SD of axonal local angles \\
\hline Axonal spline angle average & $\begin{array}{l}\text { Average of spline angles of all axonal nodes; the spline angle is the angle between the two lines passing through the node and smoothed } \\
\text { points adjacent to the node when the following two segments are approximated by a cubic spline }\end{array}$ \\
\hline Axonal spline angle standard & SD of axonal spline angles \\
\hline
\end{tabular}

Materials and Methods). The silhouette plot for the morphological data set showed a very weak group structure, with Clusters 2 and 3 containing cells with moderate positive and negative values, and all Cluster 1 cells having a negative value (Fig. $1 C$ ). The silhouette width of the data set was approximately zero, indicating that the clusters were not well separated and not significantly different from the average result of 500 trials of cluster and silhouette analysis on randomized data sets (see Table 3 ). Thus, the silhouette analysis agreed with the hypothesis that the three clusters are an arbitrary division of the data set.

As the three-cluster division produced no valid groups, we proceeded to analyze the two-cluster division found after PCA (Fig. $1 A$, purple and orange vs blue cells; division at 8 Euclidian distance squared) with the same analysis method. The twocluster division also did not have a valid group structure, with poor separation in principal component space, no distinguishing features, and a silhouette value not significantly different from random (data not shown). Based on this analysis, we concluded that there was no substructure to the morphological database, as both the two- and three-cluster PCA divisions did not withstand a more rigorous statistical examination. Therefore, the chandelier cells we recorded from appear to be morphologically homogeneous, indicative of a single, indivisible population.

\section{Physiological homogeneity of sampled chandelier cells}

We then performed a completely independent analysis of the physiological characteristics of the database of 219 recorded ChCs. We extracted 20 variables describing passive membrane properties and firing properties (Table 2) from whole-cell current-clamp recordings. The same three statistical tests were applied to determine a significant level $(p<0.05)$ of clustering. The FSS correlation filter did not remove any variables, and cluster analysis with all 20 variables was found to have no significant clusters by the bootstrap and two-tailed test. However, the best-cut test found significance at the two-cluster level (Fig. $1 E$, red and light orange clusters). For cluster analysis with PCA, the bootstrap and best-cut tests failed to find significance, while the two-tailed test found significance at the seven-, four-, three-, and two-cluster levels (Fig. 1G, green and blue clusters illustrating the two-cluster level). However, on further analysis, the two clusters found by cluster analysis with FSS correlation filter and with PCA did not correspond well to each other, with neurons from the two FSS clusters equally distributed between both PCA clusters (Fig. 1D).

As cluster analysis results using two different dimensionality reduction techniques both had significant but differing results at the two-cluster level, we chose to further analyze those divisions to test whether either could be a description of subtypes. We first analyzed the group structure of the two clusters found by cluster analysis with correlation filter (Fig. $1 E$ ). Poor separation of the clusters was evident in the silhouette plot, in which the majority of cells in the larger cluster have a negative silhouette value (Fig. $1 F)$. The silhouette width was significantly different $(p<0.01)$ from random, with a more negative value than the randomized trials indicating a lack of group structure (Table 3 ). Thus, the physiological division of ChCs using correlation filter does not appear to be a valid division.

Next, we tested the two clusters found by cluster analysis with PCA (Fig. 1G, blue and green) for group structure using the same methods as above. We reasoned that if the two clusters found by cluster analysis with PCA demonstrated evidence of group structure, we could then analyze the finer distinctions at the three-, four-, and seven-cluster levels. Indeed, the two-cluster level appeared to withstand our initial statistical analysis: in principal component space, the two clusters roughly divided the area; however, the clusters had overlapping boundaries, so these two territories were not clearly distinct (Fig. $1 H$ ). To identify potential variables that differentiated between the two groups, we performed statistical tests, finding that rheobase was the only variable with significant difference between clusters $(p<0.05$; Cluster 1, $224.26 \pm$ 
A

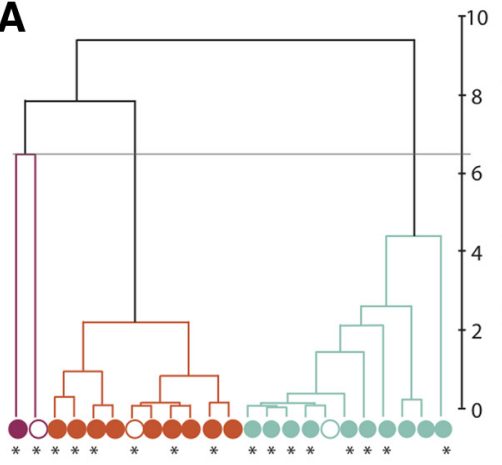

D

FSS

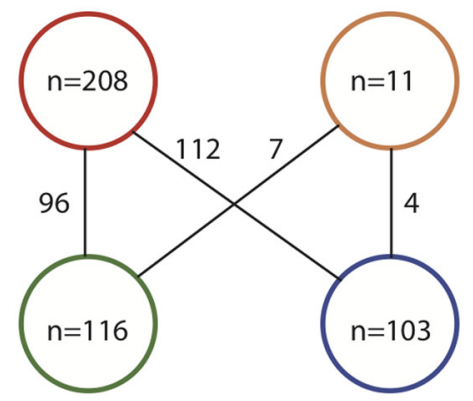

B

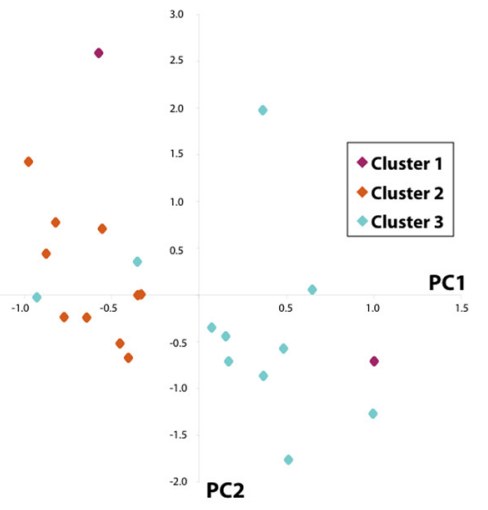

E

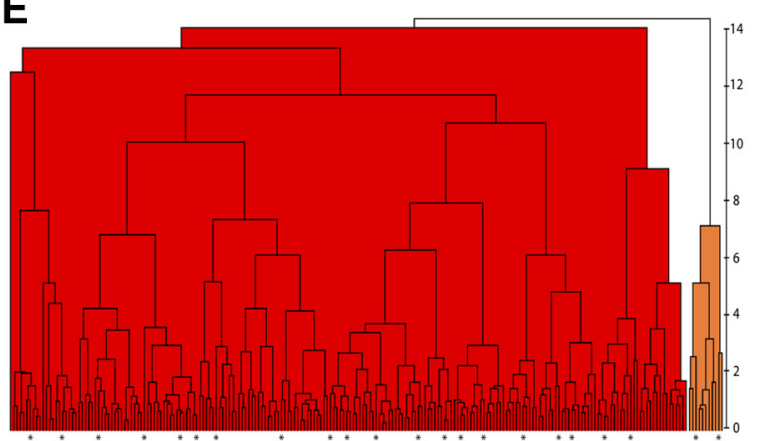

C

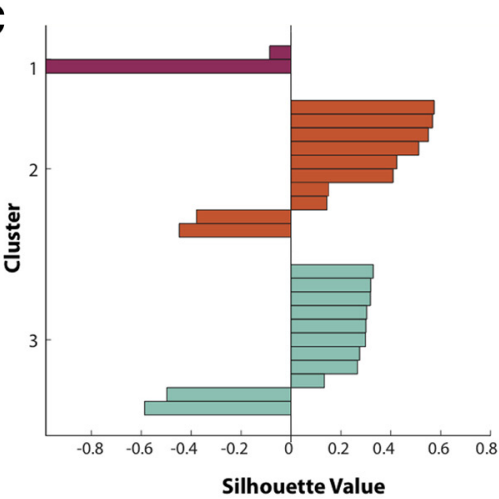

$\mathbf{F}$

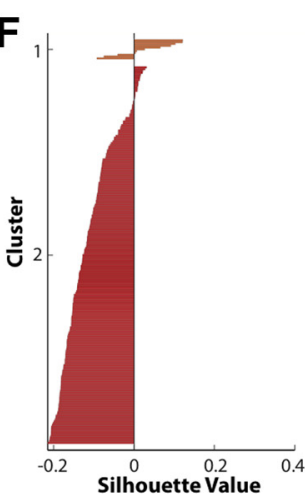

G
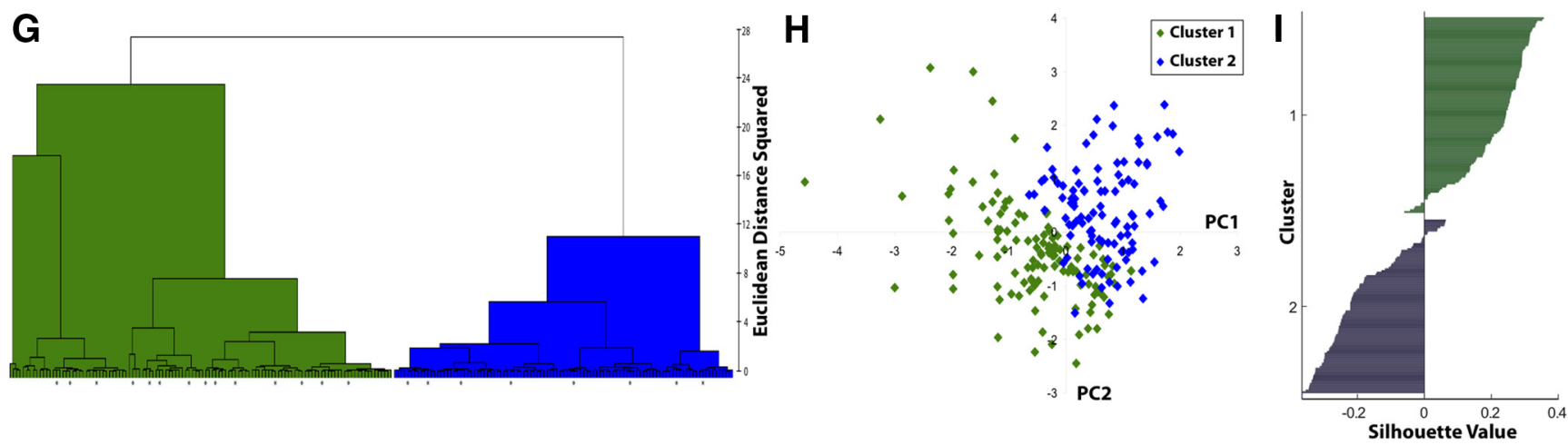

Figure 1. Cluster analysis of chandelier cells. A, Ward's method of hierarchical unsupervised cluster analysis based on 67 morphological variables applied to 23 ChCs following PCA. The cutoff linkage for three clusters is marked with a gray line, and each cluster is given a different color. Open circles indicate the centroid of the cluster. $\boldsymbol{B}$, Scatterplot in the principal component space of the three clusters shown in $\boldsymbol{A}$. C, Silhouette analysis of the three clusters shown in $\boldsymbol{A}$. D, Comparison of dimensionality reduction techniques. Map between the physiological clusters found using FSS correlation filter (top) and PCA (bottom). The numbers on the lines indicate how many cells belong to both of the clusters. $\boldsymbol{E}$, Ward's method of hierarchical unsupervised cluster analysis based on 20 electrophysiological variables applied to $219 \mathrm{ChCs}$ following correlation filter. $\boldsymbol{F}$, Silhouette analysis of two clusters shown in $\boldsymbol{E}$. $\boldsymbol{G}$, As in $\boldsymbol{E}$, but with PCA as the dimensionality reduction technique. $\boldsymbol{H}$, Scatterplot in the principal component space of the two clusters shown in $\mathbf{G}$. I, Silhouette analysis of the two clusters shown in $\mathbf{G}$.

Table 2. Physiological variables

\begin{tabular}{ll}
\hline Variable & Description \\
\hline Resting membrane potential $(\mathrm{mV})$ & Stable membrane potential when no current applied \\
Input resistance $(\mathrm{M} \Omega)$ & Calculated from small hyperpolarizing or depolarizing current steps ( $\leq 10 \mathrm{mV}$ deflection) \\
Rheobase $(\mathrm{pA})$ & Threshold current \\
AP1 amplitude $(\mathrm{mV})$ & Amplitude of the first AP \\
AP1 duration $(\mathrm{ms})$ & Time from onset of first AP, calculated as an increase $\geq 1 \mathrm{mV} / 100 \mathrm{~ms}$ to offset, calculated as return to same voltage as before AP onset \\
AP1 half-width (ms) & Time from half-amplitude during rise to halfamplitude during fall of first AP \\
AP1 rise time (ms) & Time from onset to peak of first AP \\
AP1 fall time (ms) & Time from peak to offset of first AP \\
AP1 rise rate $(\mathrm{mV} / \mathrm{ms})$ & AP1 amplitude/AP1 rise time \\
AP1 fall rate $(\mathrm{mV} / \mathrm{ms})$ & AP1 amplitude/AP1 fall time \\
AP drop $(\mathrm{mV})$ & AP1 amplitude-AP2 amplitude \\
Spike frequency adaptation & $t 2 / t 1$, where $t 1$ is the time between the peaks of the first two APs (interspike interval) and t2 is the last interspike interval \\
Frequency $(\mathrm{Hz})$ & Number of APs $/ 0.5 \mathrm{~s}$ duration of $2 \times$ threshold stimulus \\
\hline
\end{tabular}

Action potential properties were measured from the first action potential (AP1) and second action potential (AP2) in response to 500 ms twice threshold current injection. AP2 variables not listed were calculated in the same way as AP1 variables. 


\section{Table 3. Silhouette values}

\begin{tabular}{lrl}
\hline Data set & S(actual) & S(random) \pm SD \\
\hline 219 cells, electrophysiology, two clusters, FSS & -0.107 & $0.081 \pm 0.046$ \\
219 cells, electrophysiology, two clusters, PCA & 0.044 & $0.117 \pm 0.130$ \\
23 cells, morphology, three clusters, PCA & -0.050 & $0.058 \pm 0.203$ \\
23 cells, morphology, two clusters, PCA & -0.031 & $0.020 \pm 0.258$
\end{tabular}

Comparison of silhouette widths of each data set to the mean silhouette width of 500 trials of clustering randomized data \pm SD.

$72.71 \mathrm{pA}$; Cluster 2, $170.63 \pm 66.37 \mathrm{pA}$, Mann-Whitney test). To determine whether rheobase could be used as a basis to define physiological subtypes of ChCs, we analyzed the ranges of rheobase values across the two PCA clusters, finding almost identical ranges for Clusters 1 and 2 (cluster 1, 75-470 pA; Cluster 2, 60-400 pA). Therefore, cluster membership could not be determined based on rheobase, as the majority of rheobase values are included in the range of both clusters. Finally, we applied silhouette analysis, which also did not support the two clusters being distinct ChC groups. While the first cluster had predominantly positive silhouette values, the second cluster had predominately negative silhouette values, and the silhouette width was not significantly different from random (Fig. 1I; Table 3).

Overall, the electrophysiological database did not reveal clear differences among potential subtypes of ChCs. While some cluster structure was present in the two-cluster divisions of both correlation filter and PCA, these clusters were inconsistent among themselves, were not based on clearly defined differences in any electrophysiological variables, and had weak silhouette widths. Finally, even though neither clustering by morphology nor clustering by physiology variables produced meaningful subtypes of $\mathrm{ChC}$, it is possible that a multiparameter analysis is needed to define ChC subtypes. Accordingly, we performed cluster analysis based on the combined morphology and electrophysiology variables, using the 23 neurons for which we had both reconstructions and patch-clamp recordings. None of the three statistical tests found a significant level of clustering in either results using FSS or PCA (data not shown). Therefore, the simplest interpretation of our morphological and physiological analysis is that the population of neocortical ChC cells that we sampled is homogeneous.

\section{Gap junctional coupling among ChCs}

Electrical coupling between GABAergic interneurons is a common network property and has been suggested to aid in the concerted activity of interneuron populations of the same subtype (Beierlein et al., 2000). Separate support for our classification of the recorded ChCs as a homogenous population came from experiments in which we recorded from two ChCs in close proximity to each other. On 11 occasions, we found weak electrical coupling between these cells (coupling coefficient, $0.05 \pm 0.01$; $n=11$ pairs, tested bidirectionally; Fig. $2 A-C$ ). We estimate that coupling occurred in $>80 \%$ of simultaneously recorded $\mathrm{ChC}$ pairs. Aside from the frequent heterologous coupling seen for neurogliaform cells (Simon et al., 2005; Zsiros and Maccaferri, 2005), the finding of electrical coupling among ChCs is consistent with a large volume of work indicating cell-type specific electrical coupling within interneuron subtypes (Hestrin and Galarreta, 2005). At the same time, on one occasion we also encountered gap-junctional coupling between a ChC and BC (identified electrophysiologically and morphologically; Fig. $2 D, E$ ), so, although rare, it is in principle possible to find occasional coupling between $\mathrm{ChCs}$ and BCs.

\section{Dendritic polarity of ChCs}

In our anatomical study, we noticed that the dendrites of the sampled ChCs were characteristically asymmetric, predominantly targeting Layer 1 (Fig. $3 A$ ). Extensive Layer 1 dendrites and minimal arborization within Layer $2 / 3$ were not, however, consistent features, with some ChCs showing little to no preference for extending dendritic branches to Layer 1. Nevertheless, comparison of $\mathrm{ChC}$ dendritic trees with those of BCs (Fig. 3C) revealed distinct dendritic morphologies. Whereas basket cells appeared isotropic in their dendritic orientation, ChCs showed clear polarization and a preference for vertically projecting dendrites (Fig. $3 B, D$ ). We quantified the difference in Layer 1 dendrites, finding a considerable difference in the total length of L1 dendrites (ChC, $1365 \pm 198 \mu \mathrm{m}, n=8$; BC, $542 \pm 199 \mu \mathrm{m}, n=$ 6; $p<0.01$ ), which could not be attributed to differences in overall dendritic length $(\mathrm{ChC}, 1799 \pm 189 \mu \mathrm{m} ; \mathrm{BC}, 1832 \pm 312$ $\mu \mathrm{m} ; p=0.92$; Fig. $3 F$ ). Thus, the proportion of the dendritic arbor confined to Layer 1 differed significantly between ChCs and BCs (ChC, $76 \pm 6 \%, n=8$; BC, $27 \pm 8 \%, n=6 ; p<0.01$ vs ChC; Mann-Whitney two-tailed test; Fig. $3 G)$. This could not be explained simply by a difference in distance of $\mathrm{ChC}$ and $\mathrm{BC}$ somata from the Layer 1 border $(\mathrm{ChC},-10 \pm 5 \mathrm{~mm}$; BC, $-19 \pm 6$ $\mathrm{mm} ; p=0.49$; Mann-Whitney two-tailed test; Fig. $3 E)$. The chandelier cells from which we record in this study, located at the top of L2/3, therefore comprise an electrically coupled network of neurons with a preference for extending dendrites to Layer 1.

\section{Chandelier cells can promote or inhibit pyramidal neuron spiking}

After this basic morphological and electrophysiological characterization, we focused on analyzing the functional effect of $\mathrm{ChCs}$ on the spiking of pyramidal cells. To do this, we made paired recordings and assessed their impact under different experimental conditions. The first set of experiments investigated ChC impact during static membrane potential conditions, most closely approximating the so-called DOWN state observed in anesthetized or sleeping animals (Steriade et al., 1993). The second set investigated the effect of $\mathrm{ChC}$ activity in response to electrical stimulation of an afferent pathway, and the third set analyzed ChC impact during awake-like membrane potential fluctuations. Although we performed some experiments using the gramicidin perforated patch technique, the majority of experiments throughout this study were performed in whole cell, using an intracellular pipette solution that contained an elevated chloride concentration. After accounting for the different ionic concentrations in the intracellular solutions (see Materials and Methods), the reversal potential of the $\mathrm{ChC}$-pyramidal neuron synapse obtained in whole cell was not statistically different from $E_{\mathrm{GABA}}$ measured with gramicidin (whole-cell $E_{\mathrm{GABA}}$, $-54.0 \pm 0.7, n=23$; gramicidin $E_{\mathrm{GABA}},-51.4 \pm 2.2, n=17$; $p=0.20$; Fig. $4 A$ )

For the first set of experiments, pyramidal neurons were stimulated from their resting membrane potential $(-81.8 \pm 1.4 \mathrm{mV})$ with a brief current pulse of an amplitude set to semireliably evoke APs. This amplitude varied between cells and was determined before each experiment. On alternate trials, two APs separated by $20 \mathrm{~ms}$ were evoked in the presynaptic ChC before pyramidal cell stimulation (Fig. $4 B, C$ ). This evoked depolarizing GABAergic PSPs (GPSPs), which typically peaked on the second of the two PSPs (peak, $1.0 \pm 0.2 \mathrm{mV}$ ). Using this protocol, ChCs reliably increased spike probability in the postsynaptic pyramidal neuron (control, $0.46 \pm 0.05$; ChC, $0.66 \pm 0.06, n=13 ; p<0.01$; Fig. $4 D, E)$, although the magnitude of effect varied considerably 
A

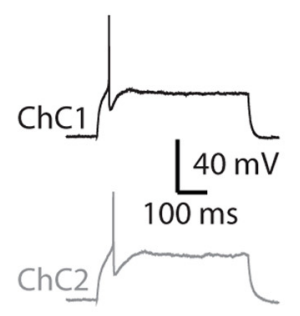

B



C

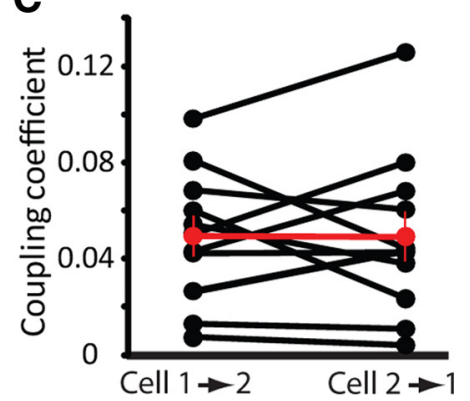

D

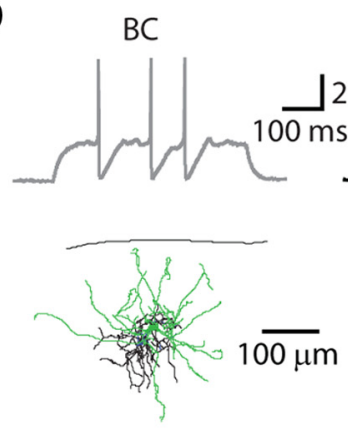

$\mathrm{ChC}$
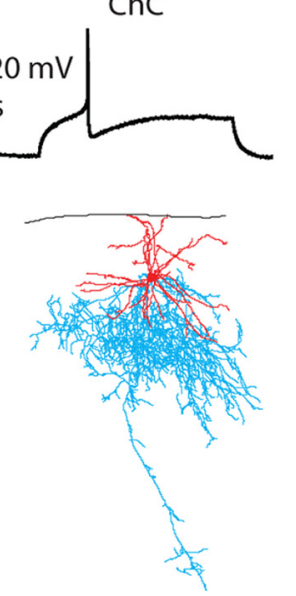

E
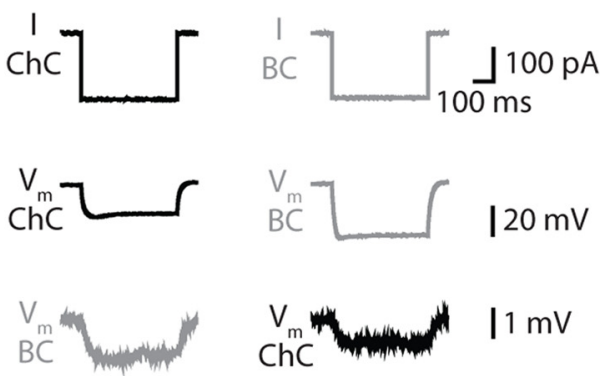

Figure 2. Electrical coupling among chandelier cells. A, Threshold spiking response of two simultaneously recorded chandelier cells. $\boldsymbol{B}$, Electrical coupling between a sample ChC-ChC pair. $\boldsymbol{C}$, Summary data from 11 pairs. D, Physiologically identified basket and chandelier cells. Morphologies are shown below, with dendrites in green (BC) or red (ChC) and axons in black (BC) or blue (ChC). $\boldsymbol{E}$, Electrical coupling was observed in the $\mathrm{BC}-\mathrm{ChC}$ pair in $\boldsymbol{D}$, taken from a P15 mouse.

between cells. We next performed the same experiment, but after having depolarized the pyramidal neuron from rest to a level that nevertheless remained below $E_{\mathrm{GABA}}\left(V_{\mathrm{m}}=-66.2 \pm 1.2 \mathrm{mV}\right)$ and that was close to reported $V_{\mathrm{m}}$ values in awake mice (Gentet et al., 2010) (different internal solutions, see Materials and Methods, Comparing $\mathrm{V}_{\mathrm{m}}$ values for different internal solutions). The ChC synapse therefore remained depolarizing (peak GPSP2, $0.5 \pm 0.1$ $\mathrm{mV}$ ) and again reliably increased pyramidal neuron spike probability (control, $0.42 \pm 0.06$; ChC, $0.55 \pm 0.07, n=8 ; p<0.01$; Fig. $4 F$ ). Depolarizing the pyramidal neuron to $E_{\mathrm{GABA}}$ or beyond reversed the $\mathrm{ChC}$ effect, with spike probability consistently decreasing from $0.56 \pm 0.06$ to $0.44 \pm 0.08(p<0.001 ; n=6$; Fig. $4 G)$. Under these slice conditions, during which the pyramidal neuron membrane potential is essentially static while receiving ChC input, chandelier cells of cortical Layer $2 / 3$ can therefore both promote or inhibit pyramidal neuron output, depending on the pyramidal neuron membrane potential.

The above experiments were performed with the GPSP preceding the current injection by $30 \mathrm{~ms}(\Delta t=+30 \mathrm{~ms})$. We also performed the same experiments for $\Delta t=+5$ or $\Delta t=+15 \mathrm{~ms}$, to assess the impact of the underlying $\mathrm{GABA}_{\mathrm{A}}$ conductance change on the ability to promote spiking. For both time points, the depolarization provided by the ChC GPSP overcame the inhibitory shunt provided by channel opening, leading to increases in spike probability [normalized probability of an action potential, $\mathrm{p}$ (AP) $+5 \mathrm{~ms}, 1.8 \pm 0.5, p=0.06 \mathrm{vs}$ control; $+15 \mathrm{~ms}, 1.6 \pm 0.1, p<$ $0.001 ;+30 \mathrm{~ms}, 1.4 \pm 0.2, p<0.05)$. We expect the conductance effect to be stronger at shorter time intervals, although we did not check. However, it should be noted that the $\mathrm{ChC}$ synapse is quite electrotonically isolated from the source of glutamatergic excitation on dendritic spines, and that by using somatic current injection rather than dendritic inputs, we are likely overestimating the true shunt provided by the $\mathrm{ChC}$ synapse on excitatory synaptic inputs.

\section{Electrical stimulation of Layer 1 enforces ChC-mediated feedforward inhibition}

As described above, the ChCs from which we recorded frequently had numerous dendrites extending into Layer 1, and it would therefore seem that the majority of afferent excitation will arise through this pathway. Although in principle many other types of interneurons, such as basket cells, could be activated by Layer 1 inputs, the peculiar asymmetric dendritic morphology of ChCs could make them particularly tuned to Layer 1 activation. To study this, and because the primary target of Layer $2 \mathrm{ChCs}$ is Layer $2 / 3$ pyramidal neurons, whose apical dendrites also extend into Layer 1, we used electrical stimulation of this uppermost cortical layer to assess the impact of ChC activation on Layer $2 / 3$ pyramidal neurons (Fig. 5A).

A glass stimulating electrode containing ACSF was placed approximately midway between the pia and Layer 2, 50-150 $\mu \mathrm{m}$ laterally displaced from the location of the ChC and pyramidal neuron cell bodies. For ChCs to influence pyramidal neurons, ChCs must be recruited both more easily than and before their postsynaptic partners. We found this to be the case for all ChC-pyramidal neuron synapse pairs recorded from (Fig. $5 B$ ). Chandelier cells required $72 \pm 3 \mu \mathrm{A}$ and 
A
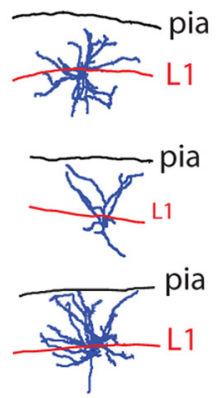

C
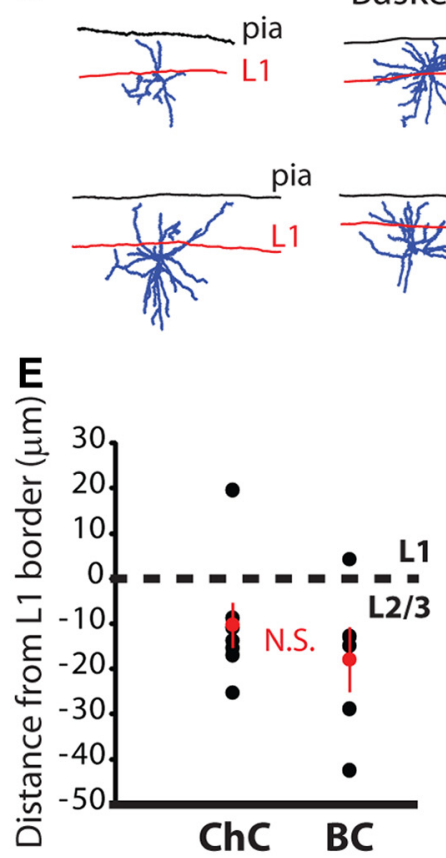

Chandelier cells

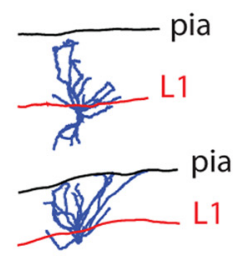

$\overline{3}^{202}$

$\overline{100 \mu \mathrm{m}}$

Basket cells

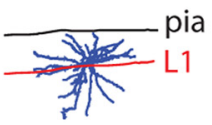

${ }^{\mathrm{Lia}}$

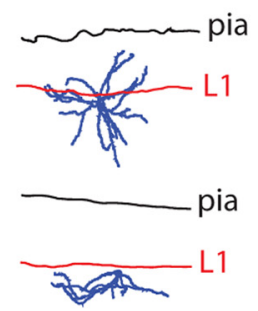

F

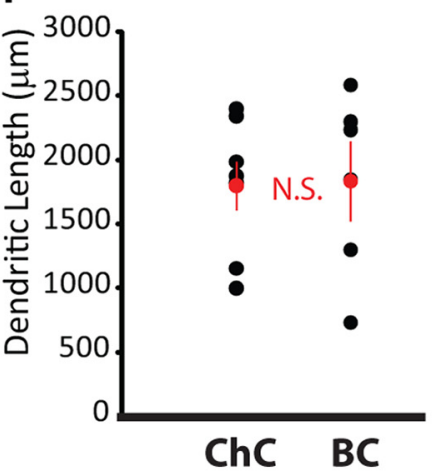

B
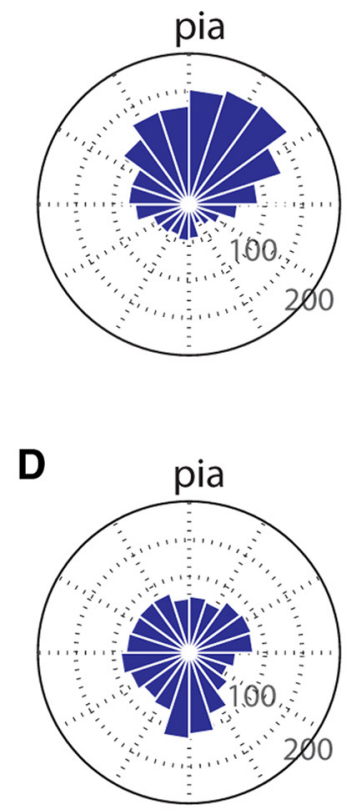

G

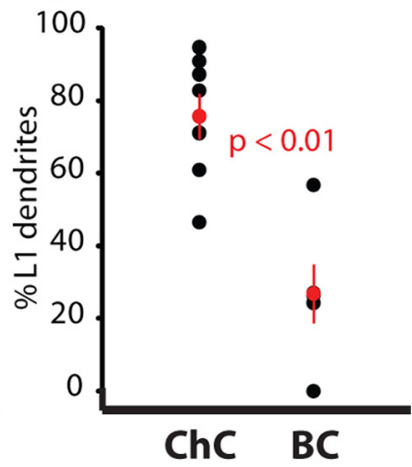

Figure 3. Dendritic morphology of upper Layer $2 / 3$ chandelier and basket cells. $\boldsymbol{A}$, Neurolucida reconstructions of ChCs used for analysis of dendritic Layer 1 preference. $\boldsymbol{B}$, Polar plot of dendritic length and location. Neuronal somata are located at center of plots, and the average dendritic length across cells is plotted in $18^{\circ}$ bins. The pia is at the top, and distance is indicated by dashed circles. $\boldsymbol{C}, \boldsymbol{D}$, Same as for $\boldsymbol{A}$ and $\boldsymbol{B}$ for basket cells. $\boldsymbol{E}$, Location of ChC and BC somata relative to the L1-L2/3 border. $\boldsymbol{F}$, Total dendritic length for ChCs and BCs. $\boldsymbol{G}$, Proportion of ChC and BC dendrites located in Layer 1. Remaining dendrites were in Layer 2/3. Error bars indicate SEM.

pyramidal neurons $135 \pm 7 \mu \mathrm{A}$ to be activated $(n=10$; $p<0.001)$.

At the stimulation strength required to activate ChCs, we measured pyramidal neuron $V_{\mathrm{m}}$ at the onset of the IPSP, taken here to be $1 \mathrm{~ms}$ after the peak of the presynaptic spike. Pyramidal neurons were consistently below $E_{\mathrm{GABA}}$ for that particular synapse at the onset of the GPSP $\left(V_{\mathrm{Pyr}}=-68.1 \pm 0.1 \mathrm{mV} ; E_{\mathrm{GABA}}=\right.$ $-57.2 \pm 1.2 \mathrm{mV} ; n=10 ; p<0.001$; Fig. $5 C, D)$. The peak voltage reached by the EPSP in response to Layer 1 stimulation was $-60.4 \pm 2.1 \mathrm{mV}$, not significantly different from $E_{\mathrm{GABA}}$. Thus, at IPSP onset, the ChC synapse is depolarizing, but rapidly switches to a predominantly shunting effect during Layer 1 stimulation. Although the ChC GPSP was depolarizing and thus potentially excitatory, we were unable to directly assay the impact on pyramidal neuron spiking without further increasing stimulation intensity. We increased stimulation strength to enable pyramidal neuron spiking, which decreased the latency of the $\mathrm{ChC}$ spike and allowed it to influence the pyramidal neuron (Fig. 5C). At this stimulation intensity, the more rapid rise of the pyramidal neuron $V_{\mathrm{m}}$ converted the ChC synapse to shunting at GPSP onset and hyperpolarizing immediately before spike generation (Fig.
$5 C, E)$. To measure the effect of $\mathrm{ChC}$ activation on pyramidal neurons during this protocol, we applied large hyperpolarizing pulses to the $\mathrm{ChC}$ on alternate trials to prevent $\mathrm{ChC}$ spikes (Fig. 5F). The consequent absence of $\mathrm{ChC}$ spikes was associated with an increase in pyramidal neuron spiking, revealing that under these conditions, chandelier cells decrease pyramidal neuron spike probability (control, $0.57 \pm 0.1$; ChC, $0.39 \pm$ $0.1, n=6$; $p<0.01$; Fig. $5 G$ ). This effect confirmed that the $\mathrm{ChC}$ was indeed firing before the pyramidal neuron and that the readout of the pyramidal neuron spike was not drastically affected by the relatively high $R_{\text {series }}$ of the perforated patch configuration. Electrical stimulation of cortical Layer 1 therefore recruits a ChC-mediated feedforward inhibition of Layer 2/3 pyramidal neurons.

\section{ChC effect during in vivo-like noise stimulation}

We next performed experiments aimed at approximating, as closely as possible, the conditions under which Layer $2 / 3$ cortical pyramidal neurons have been reported to fire in the awake animal. To do this, we generated a filtered white noise stimulus whose peak-to-peak amplitude and depolarizing offset could be 
A

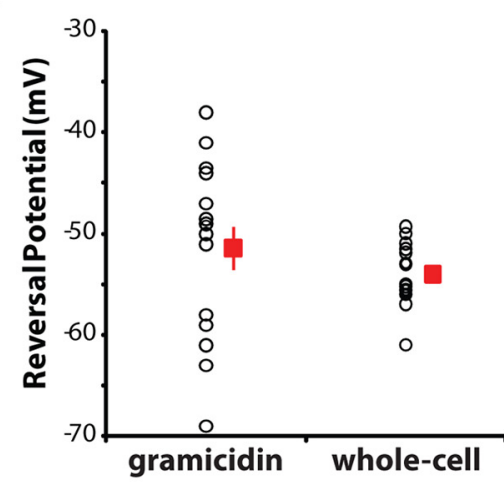

B
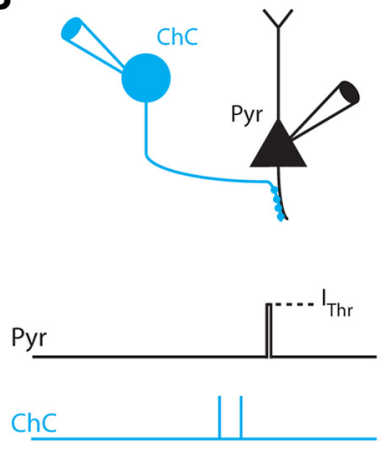

C
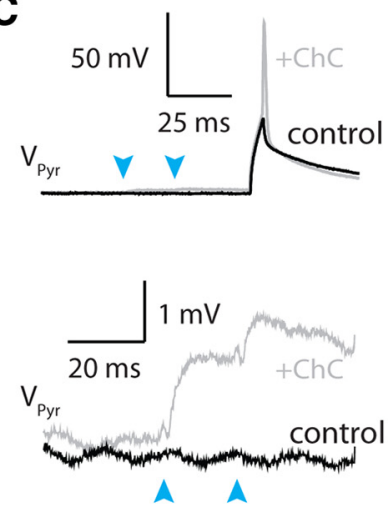

D

$$
\begin{aligned}
& \text { AP } \\
& \text { no AP }
\end{aligned}
$$

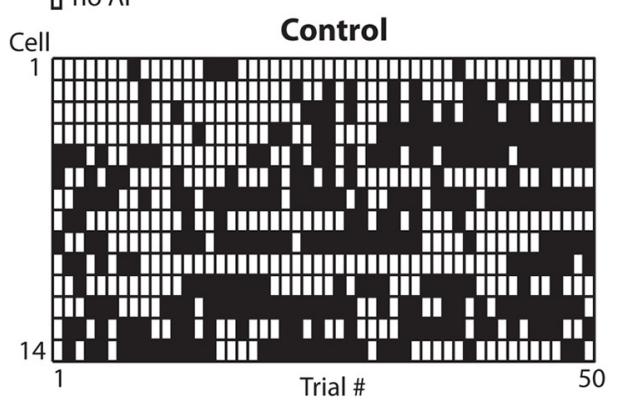

E

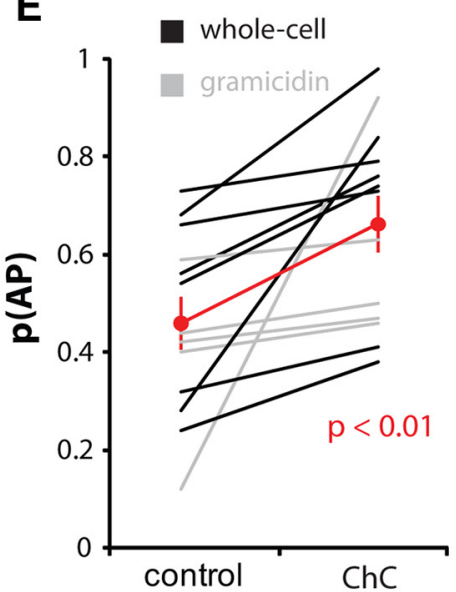

F

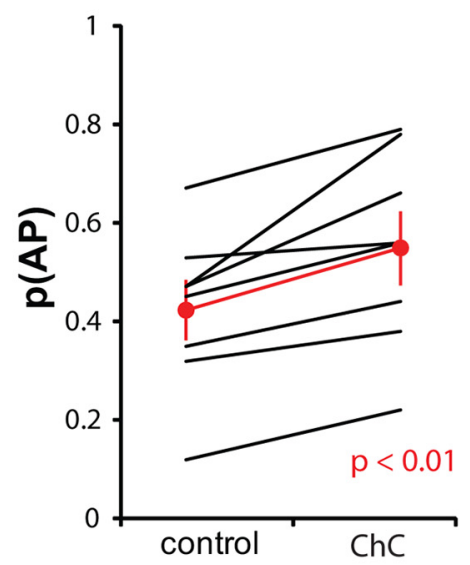

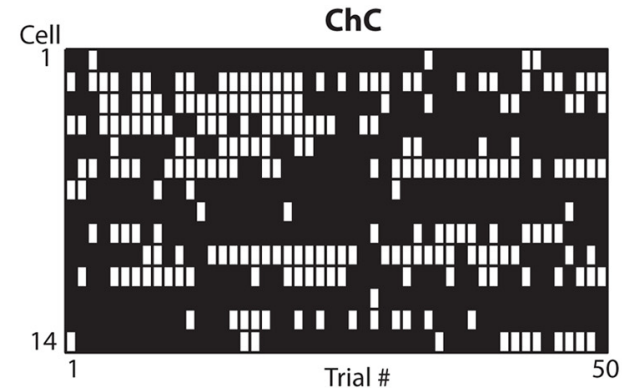

G

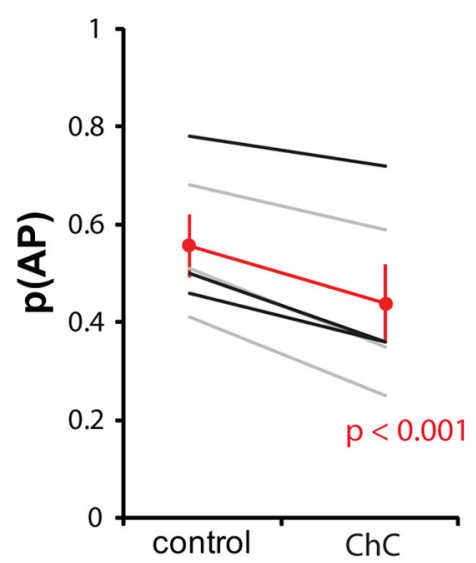

Figure 4. Chandelier cells can both excite and inhibit postsynaptic pyramidal neurons. $\boldsymbol{A}, \mathrm{GABA}_{\mathrm{A}}$ reversal potential recorded with gramicidin perforated patch, or in whole cell using an elevated internal chloride concentration. Inset, Traces from one pair recorded in whole cell, voltage clamped at -80 to $-40 \mathrm{mV}$. Calibration: $10 \mathrm{pA}, 10 \mathrm{mV}$. $\boldsymbol{B}, \mathrm{Schematic}$ of the recording configuration. $\boldsymbol{C}$, Example traces from a pyramidal neuron during control (black) and stimulation (gray) trials. Bottom, Expanded traces to illustrate depolarizing $C h C$ input. $\boldsymbol{D}$, Trial-by-trial plots of pyramidal neuron spiking for individual experiments. $\boldsymbol{E}-\mathbf{G}$, Summary graphs for pyramidal neurons at rest $(\boldsymbol{E})$, depolarized but below $E_{\mathrm{GABA}}(\boldsymbol{F})$, and depolarized above $E_{\mathrm{GABA}}(\boldsymbol{G})$. Error bars indicate $\operatorname{SEM}$.

adjusted (Fig. 6A, left). Although neuronal membrane potential fluctuates considerably during both the resting and actively behaving states (Crochet et al., 2011), the period immediately preceding spike generation in Layer 2/3 pyramidal neurons is highly stereotyped, being characterized by a moderately large amplitude, cell-specific depolarization (Poulet and Petersen, 2008; Gentet et al., 2010). For each recording, we adjusted both the depolarizing offset and peak-to-peak amplitude to achieve a mean membrane potential of approximately $-60 \mathrm{mV}(-62.5 \pm$ $1.2 \mathrm{mV} ; n=10$; Fig. $6 C$ ). Thus, $E_{\mathrm{GABA}}$ at the $\mathrm{ChC}$ synapse $(-52.3 \pm 1.5 \mathrm{mV})$ lies between the mean $V_{\mathrm{m}}$ and action potential threshold $(-43.7 \pm 1.9 \mathrm{mV}$; Fig. $6 \mathrm{D})$. In the $20 \mathrm{~ms}$ before the pyramidal neuron spike, the PSD averaged $16.1 \pm 1.9 \mathrm{mV}$, with an average $d V / d t$ value of $0.7 \pm 0.1 \mathrm{mV}$ (Fig. 6C). The PSD amplitude is comparable to but slightly larger than those recorded from awake behaving mice (Poulet and Petersen, 2008), and within the range recorded from anesthetized cats (Azouz and Gray, 2008).

After recording 200 sweeps of the white noise stimulus, we created a histogram of the pyramidal neuron spike times (Fig. 6A, right) and built a stimulation protocol to activate the $\mathrm{ChC}$ at various defined times before the expected pyramidal neuron spike $\left(t_{\mathrm{pyr}}\right)$. We also activated the $\mathrm{ChC}$ after $t_{\mathrm{pyr}}$. This served as a control, allowing us to compare spike probability under conditions in which $\mathrm{ChC}$ activation preceded or followed (and could or could not influence) pyramidal neuron spikes (Fig. $6 B$ ). After defining the four $\Delta t$ intervals of the ChC spikes (three before and one following the pyramid 
A

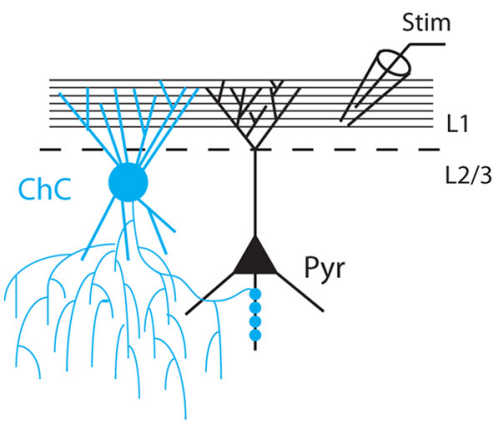

B

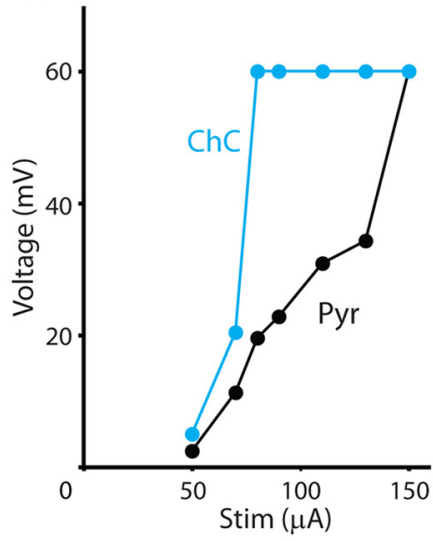

D

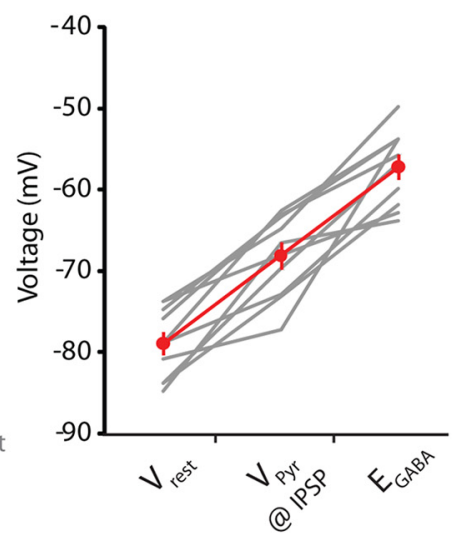

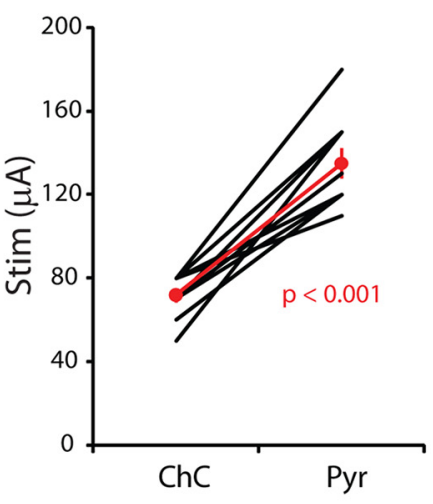

E

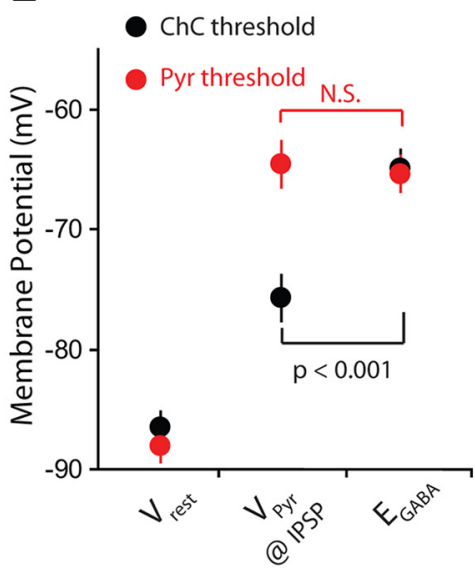

F
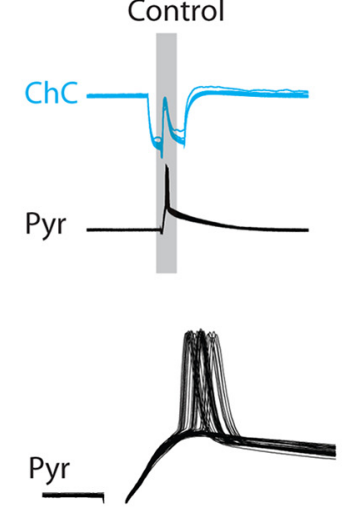
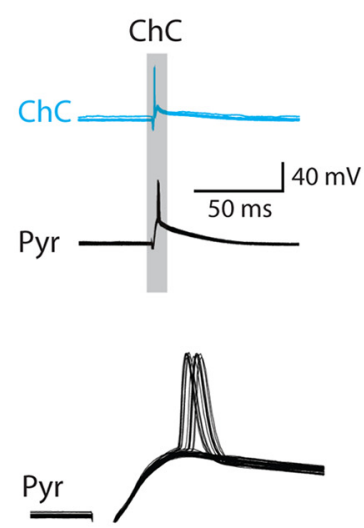

G

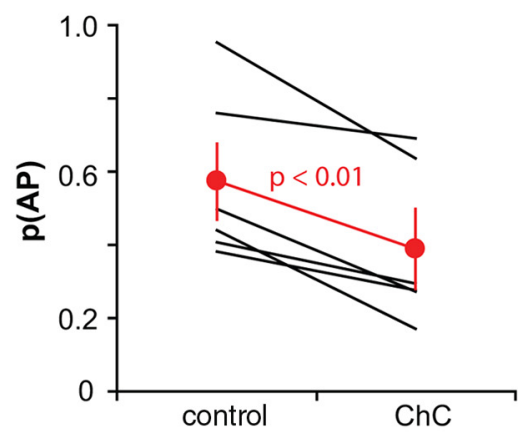

Figure 5. Electrical stimulation of Layer 1 recruits ChC-mediated inhibition. $\boldsymbol{A}$, Schematic of the recording configuration. Pyramidal neurons were recorded with gramicidin. $\boldsymbol{B}$, Left, Recruitment of $\mathrm{ChC}$ (blue) and pyramidal neuron to increasing stimulation strengths. Action potential amplitude is indicated by a voltage of $60 \mathrm{mV}$. Right, Summary data showing the minimum stimulation intensity required to evoke spikes in $100 \%$ of trials for ChCs and pyramidal neurons. C, Responses of recorded neurons at two stimulation intensities, ChC threshold (left) and pyramidal neuron threshold (right). $\boldsymbol{D}$, Cell-by-cell plot of the relationship between $E_{\mathrm{GABA}}$ and the ChC GPSP at the stimulation intensity required for ChC activation. $\boldsymbol{E}$, ChC GPSP polarity depends on the strength of afferent stimulation. $\boldsymbol{F}$, Assaying ChC effect on pyramidal neuron spiking by applying large hyperpolarizing pulses to the ChC on alternate trials. $\mathbf{G}$, At the stimulation strength required to activate pyramidal neurons, ChCs are strictly inhibitory. Error bars indicate SEM.

spike), the presentation of ChC spike times was randomized from trial to trial in an attempt to nullify the effect of any transient changes in pyramidal neuron excitability (Fig. 6B).

Under these conditions, ChCs produced reliable inhibition when activated shortly before the expected pyramidal neuron spike $(\Delta t=$ $+5 \mathrm{~ms}$; Fig. 7A). Average spike probability decreased by $48.2 \pm$ $8.1 \%$, from $0.53 \pm 0.03$ to $0.27 \pm 0.04$, an effect that was also apparent in the majority of individual experiments (Fig. 7A). In contrast, activation of the ChC at earlier time points, either 15-20 or 30-40 $\mathrm{ms}$ before the pyramidal neuron spike, did not produce a consistent effect. The majority of experiments failed to show significant increases or decreases in $\mathrm{p}(\mathrm{AP})$, instead exhibiting small, statistically insignificant modulations in both directions. However, in some cells, ChC activation at these time points had robust effects on pyramidal neuron spiking, twice strongly decreasing and once strongly increasing $\mathrm{p}(\mathrm{AP})$ (Fig. 7A, black dots; $p<0.01$ ). Across all experi- 
ments, the mean $\mathrm{p}(\mathrm{AP})$ changed by $+4.6 \pm$ $4.0 \%$ for $\Delta t=+30-40 \mathrm{~ms}$, and by $-5.6 \pm$ $6.7 \%$ for $\Delta t=+15-20 \mathrm{~ms}$ (Fig. 7A).

These experiments clearly show an inhibitory action of ChCs, but suggest little if any facilitatory effect, even though we observed a moderate but significant relationship between the change in $\mathrm{p}(\mathrm{AP})$ and the calculated driving force (DF) at the time of GPSP onset (Fig. $7 B ; R^{2}=0.42$; $p<0.001$; linear regression followed by ANOVA). Although this suggested that depolarizing GPSPs should be capable of promoting spike generation, removal of the hyperpolarizing GPSPs associated with the $\Delta t=+5 \mathrm{~ms}$ condition (Fig. $7 B$, black diamonds) eliminated the relationship between DF and $\mathrm{p}(\mathrm{AP})\left(R^{2}=0.001\right.$; $p=0.88$ ).

One would expect the driving force to be an important determinant of the effect of a synapse. However, under our conditions, as in the intact brain, the driving force is dynamic and, during the PSD, decreases with time for depolarizing GPSPs; that is, during the prespike depolarization, $V_{\mathrm{m}}$ typically starts below $E_{\mathrm{GABA}}$, and rapidly approaches and crosses this value. Thus, for two of our three ChC stimulation conditions $(\Delta t=+30-40 \mathrm{~ms} ; \Delta t=$ $+15-20 \mathrm{~ms}$ ), the driving force changes with time from moderately positive, to zero, to negative. To address this issue, we measured $E_{\mathrm{GABA}}$ for each of the 10 cell pairs and used these values to determine the change in DF over time during the filtered white noise protocol. We convolved this DF with the ChC GPSC conductance determined for each cell (at $-60 \mathrm{mV}$ ) to determine the current flux through the $\mathrm{ChC}$ synapse as a function of time. Using this approach, we routinely observed inward currents for $\Delta t=$ $+30-40 \mathrm{~ms}$, outward currents for $\Delta t=5$ $\mathrm{ms}$, and currents that switched from inward to outward for $\Delta t=+15-20 \mathrm{~ms}$ (Fig. 7C). Surprisingly, we observed only a moderate relationship between the integrated current flux and spike probability $\left(R^{2}=0.13 ; p=\right.$ 0.11 ; Fig. $7 D)$, perhaps suggesting cell-tocell variations in the activation of subthreshold voltage-gated channels.

Finally, we calculated the absolute voltage contribution of the ChC GPSP to the probability of pyramidal neuron spiking. Because average $V_{\mathrm{m}}$ and ChC synapse $E_{\mathrm{GABA}}$ have similar values, the $\mathrm{ChC}$ GPSP is expected to be small and is not readily detectable among the large fluctuations we used to drive the pyramidal neurons. We isolated the ChC GPSP for $\Delta t=+30-40$ and for $\Delta t=+15-20 \mathrm{~ms}$ by averaging all sweeps at those two time points and subtracting from that the averaged control trace, $\Delta t=-50 \mathrm{~ms}$ (Fig. $7 E$ ). In each cell, the peak GPSP was depolarizing for both time points, although this did not necessarily imply an increase in $\mathrm{p}(\mathrm{AP})$ (Fig. $7 F$ ). However, when measuring the GPSP amplitude immediately before the onset of the averaged spike envelope, we observed a robust relationship
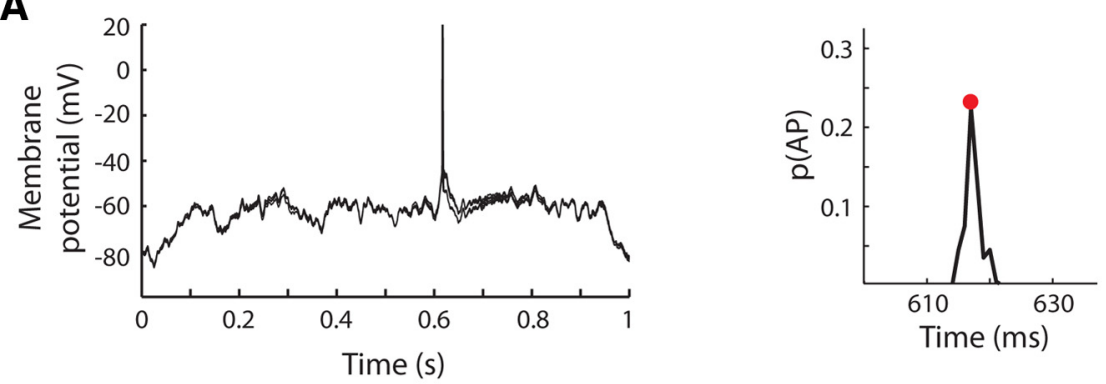

B
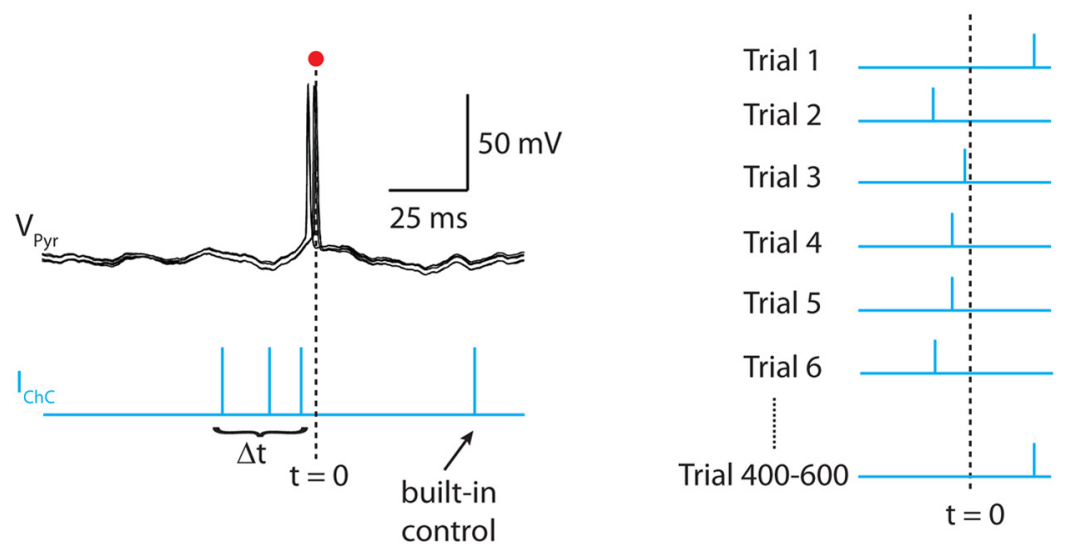

C

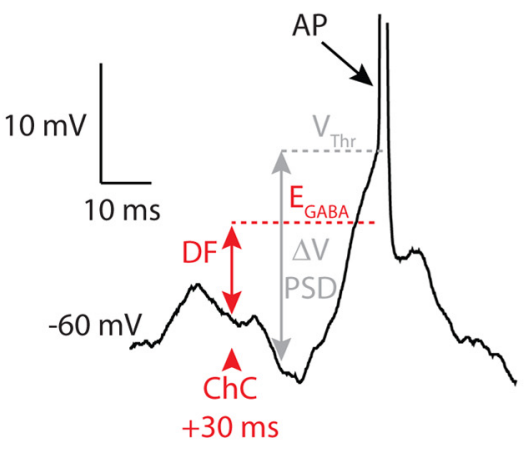

D

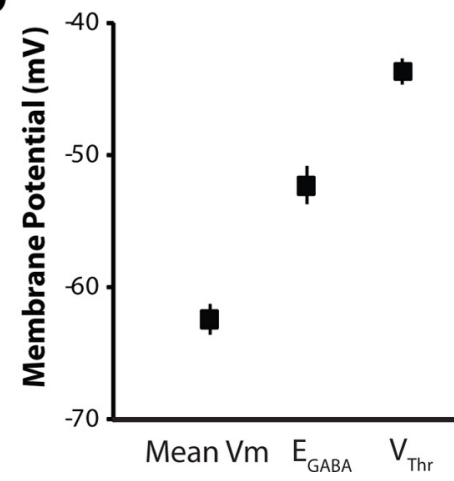

Figure 6. Investigating ChC impact during in vivo-like $V_{\mathrm{m}}$ fluctuations. A, Five overlaid sweeps of pyramidal neuron membrane potential during the white noise stimulation. Right, Spike-time histogram determined from 200 sweeps of the noise stimulation 列 列 is the voltage difference between the spike threshold $\left(V_{\text {Thr }}\right)$ and $V_{\mathrm{m}} 20 \mathrm{~ms}$ before spike onset. $\boldsymbol{D}$, Plot showing the relationship between the mean $V_{\mathrm{m}}$ during white noise stimulation, $E_{\mathrm{GABA}}$ and $V_{T h r}$ across all experiments. Error bars are SEM.

with spike probability (Fig. $7 G$ ). This is not surprising in itself, but the strength of the relationship suggests that the small and statistically insignificant changes in $\mathrm{p}(\mathrm{AP})$ are not fluctuations due simply to experimental noise or chance, but instead are due directly to the small depolarizations or hyperpolarizations provided by the $\mathrm{ChC}$ synapse.

\section{Discussion}

Homogeneity of upper-layer ChCs across genetic background and cortical areas

Conflicting results on the polarity of $\mathrm{ChC} E_{\mathrm{GABA}}$ in hippocampus and cortex raise the possibility that the function of ChCs may be heterogeneous (Glickfeld et al., 2009), depending perhaps on the brain region or reflecting a basic morphological or physiological 
A

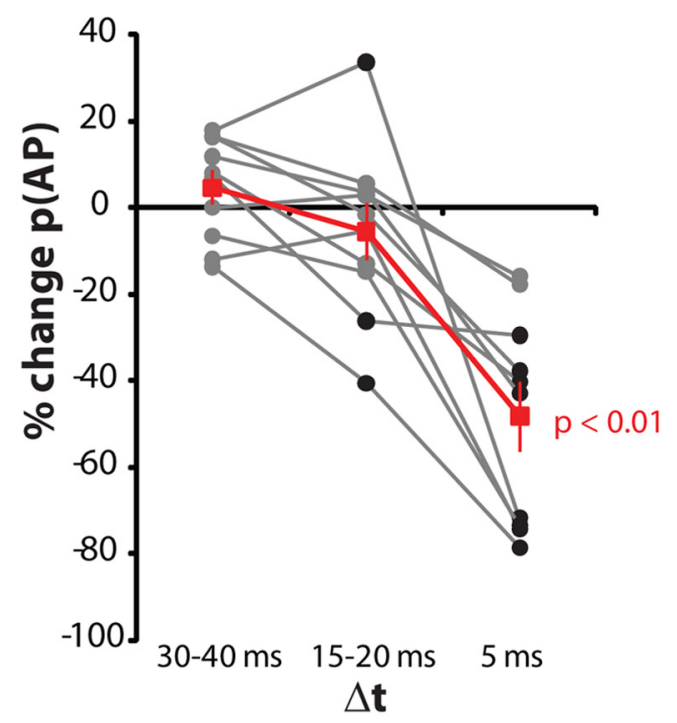

C

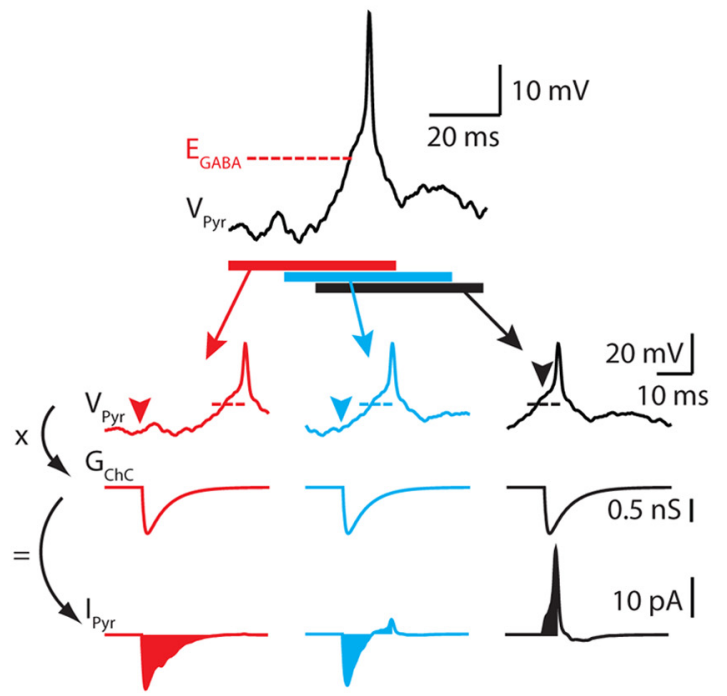

E

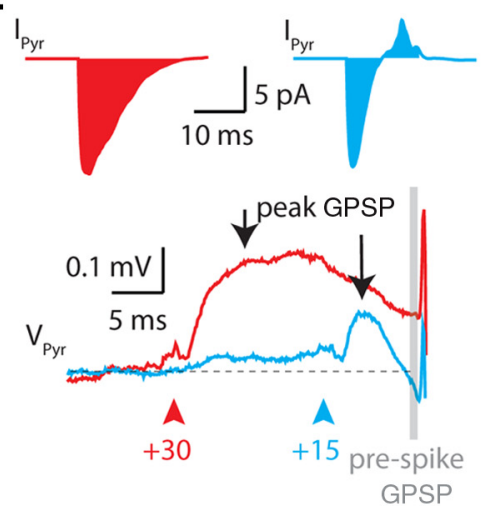

B

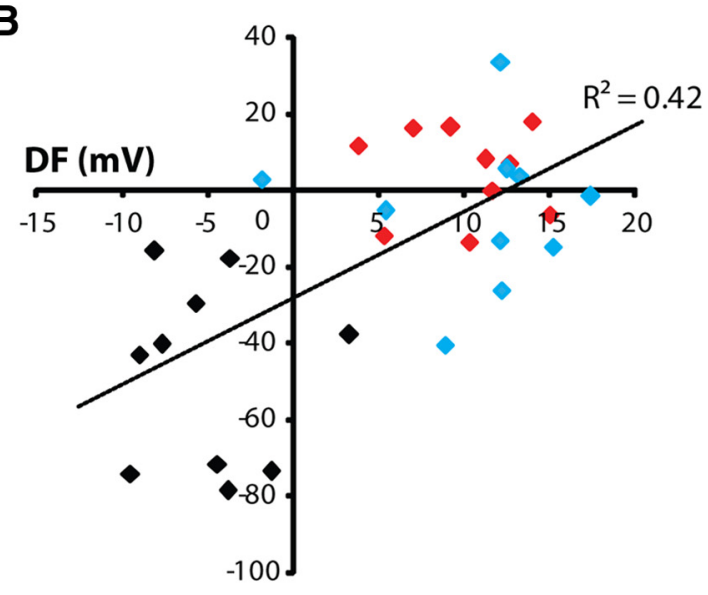

$\%$ change AP

D

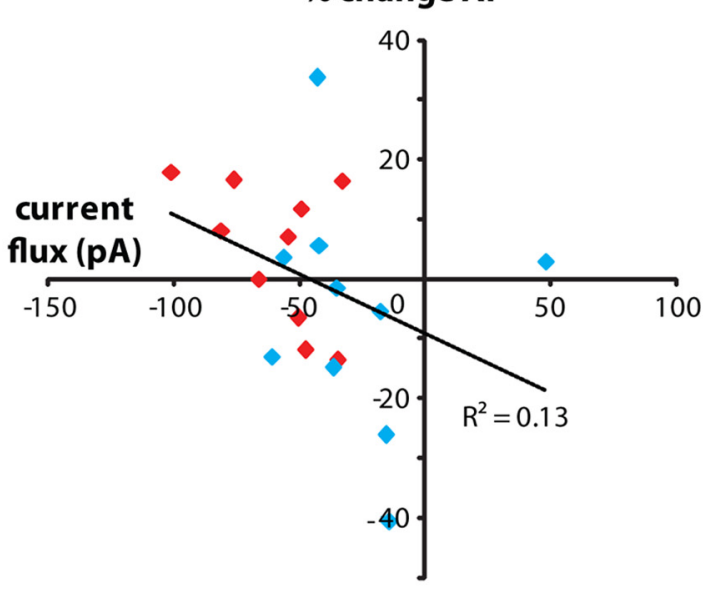

Figure 7. Chandelier cell effect during in vivo-like $V_{\mathrm{m}}$ fluctuations. $A$, Summary data for all experiments. Black symbols indicate significant deviations from control [0\% change in $\left.\mathrm{p}(\mathrm{AP})\right]$ for an individual experiment $\left(\chi^{2}\right.$ test). Red symbols are means across all experiments. Error bars indicate SEM. B, Relationship between driving force and $p(A P)$ for the three time points. Black symbols, +5 $\mathrm{ms}$; blue symbols, $+15-20 \mathrm{~ms}$; red symbols, $30-40 \mathrm{~ms}$. C, Calculation of the total ChC-mediated current flux. The average spike response under control conditions ( $-50 \mathrm{~ms}$, top trace) was zeroed at $E_{\mathrm{GABA}}$ to calculate the driving force, which was then convolved with the synaptic conductance to calculate total current flux. Arrowheads indicate time of $\mathrm{ChC}$ activation for each condition (colored as in $\boldsymbol{B}$ ). Dashed lines indicate $E_{\mathrm{GABA}}$. $\boldsymbol{D}$, Relationship between total current flux and p(AP). Only data for $+15-20 \mathrm{~ms}$ (blue) and $+30-40 \mathrm{~ms}$ (red) time points are shown. $\boldsymbol{E}$, Sample traces of the average ChC-evoked GPSP, showing measurement locations for peak (arrows) and prespike GPSPs (gray bar). ChC spike time is indicated by arrowheads. Top, Current flux for the two GPSPs shown below. The polarity switch for the $+15 \mathrm{~ms}$ current flux is reflected in the isolated GPSP. $\boldsymbol{F}$, Relationship between $\mathrm{p}(\mathrm{AP})$ and peak GPSP amplitude. G, relationship between $\mathrm{p}(\mathrm{AP})$ and prespike GPSP amplitude. Arrows indicate the GPSPs in $\boldsymbol{E}$. 
heterogeneity among chandelier cells. In our study, we therefore first explored whether different subtypes of neocortical ChCs exist by applying a rigorous series of unsupervised classification methods to a relatively large database of 219 ChCs. As clustering by both morphology and electrophysiology gives no evidence for subtypes of ChCs, we conclude that our data set of ChCs cannot be divided into statistically valid subgroups. Moreover, we used two different genetic strategies to label subsets of interneurons in the G42 and Nkx2.1 mouse lines and found no statistical difference in the morphological or physiological properties of cells from these two different genetic backgrounds. Finally, we sampled cells from 10 different cortical areas, finding no evidence that they differ systematically. Therefore the ChCs from which we recorded represent a homogeneous population that cannot be clearly subdivided according to morphological or physiological characteristics, genetic strains, or cortical areas.

\section{A state-dependent function of ChCs}

We also investigated the functional impact of this homogeneous ChC population on the firing of Layer $2 / 3$ pyramidal neurons. We show that the ability of cortical ChCs to excite their postsynaptic targets is critically dependent on $E_{\mathrm{GABA}}$ and the membrane potential trajectory of the postsynaptic neuron. When $V_{\mathrm{m}}$ is essentially static, as in DOWN states, depolarizing GPSPs can have an excitatory influence, facilitating spike generation. Since spiking during the DOWN state is rare, our results may be more applicable to DOWN-UP state transitions, when a hyperpolarized, static $V_{\mathrm{m}}$ rapidly depolarizes due to a barrage of synaptic activity. The excitatory influence we observe occurs for latencies (or $\Delta t$ ) between +30 and $+5 \mathrm{~ms}$ and is seen in a quiescent slice preparation, but also at more depolarized levels closer to the average $V_{\mathrm{m}}$ seen in vivo. The main requirement for excitation appears to be that the majority of ChC-mediated current flux occurs before the neuronal $V_{\mathrm{m}}$ crossing $E_{\mathrm{GABA}}$. Our current injection experiments (Fig. 4), in which ChCs were activated before the pyramidal neuron being depolarized, allowed ChCs to excite their targets. In contrast, our electrical stimulation experiments (Fig. 5), in which ChCs were activated during the rising phase of the pyramidal neuron EPSP, consistently showed ChC-mediated inhibition. Under conditions of constantly fluctuating $V_{\mathrm{m}}$, as is characteristic of neurons in awake animals, the only robust effect observed was spike inhibition, with no consistent direction of effect for time intervals of $15 \mathrm{~ms}$ or more. Our inability to detect an effect of ChCs - either excitatory or inhibitory - at all but the shortest $\Delta t$ intervals may partly reflect the fact that we manipulate only a single ChC. Based on counts of boutons apposed to the axon initial segment (AIS), a single pyramidal neuron has been estimated to receive input from three to six ChCs (Buhl et al., 1994; Tamas and Szabadics, 2004). Temporally coordinated activation of ChCs, perhaps facilitated by the electrical coupling we describe, would therefore be expected to produce significantly larger GPSPs. In addition to producing stronger inhibition, simultaneous activation of ChCs may also enable a more overt excitatory effect on postsynaptic spiking, based on the relationship we found between prespike GPSP amplitude and spike probability.

Our results show that chandelier cells, like other interneurons, can inhibit spiking and can do so quite strongly if the pyramidal cell is active. But simple inhibition, in the absence of excitation, is unlikely to be the only function of chandelier cells. An alternative view is to consider the ChC synapse not in terms of its direct effect on spike output, but rather in terms of its impact on neuronal excitability. We took care in our experiments to make the average
$V_{\mathrm{m}}$ during noise stimulation approximate that observed in vivo (our experiments, approximately $-63 \mathrm{mV}$; in vivo, approximately $-55 \mathrm{mV}$; different internal solutions; see Materials and Methods, Comparing $V_{\mathrm{m}}$ values for different internal solutions). The $E_{\mathrm{GABA}}$ of the ChC synapse then lies slightly depolarized relative to average $V_{\mathrm{m}}$. This is analogous to a recent study examining the subthreshold mechanisms underlying responses of L2/3 pyramidal neurons to whisker touch (Crochet et al., 2011), in which the reversal potential of the synaptic response to whisker contact-reflecting combined excitatory and inhibitory currentslies above the average $V_{\mathrm{m}}$ but typically below spike threshold. Variations in the reversal potential of the synaptic response correlated strongly with the excitability of the neuron. The $\mathrm{ChC}$ synapse may perform a similar function, helping to set the excitability of the neuron by means of its reversal potential.

Consistent with this possibility, our gramicidin recordings in fact revealed considerable variability in $E_{\mathrm{GABA}}$, and various studies have indicated that $\mathrm{GABA}_{\mathrm{A}}$ reversal potential is not static (Wagner et al., 1997; Woodin et al., 2003; Fiumelli et al., 2005; Choi et al., 2008). Two studies in particular relate shifts in $E_{\mathrm{GABA}}$ to activity-dependent modulation of NKCC1, the cation-chloride cotransporter present at the AIS (Khirug et al., 2008). In the first, repeated action potential activity was shown to cause a persistent increase in intracellular chloride accumulation via alterations in the $\mathrm{Na}^{+}-\mathrm{K}^{+}-\mathrm{ATPase}$ transporter and NKCC1 (Brumback and Staley, 2008). Since NKCC1 is expressed at the AIS, changes in $E_{\mathrm{GABA}}$ at the ChC synapse may occur naturally as a function of the spike output of the postsynaptic neuron, with high levels of activity leading to a depolarizing shift in $E_{\mathrm{GABA}}$ and increasing neuronal excitability. In the second study, near-coincident firing of presynaptic and postsynaptic cells caused a hyperpolarizing shift in $E_{\mathrm{GABA}}$ via NKCC1 alterations (Balena and Woodin, 2008), effectively increasing the strength of inhibition and decreasing excitability. Thus, mechanisms exist to bidirectionally shift $E_{\mathrm{GABA}}$ via changes in $\mathrm{NKCC} 1$ activity, and may explain the large variability we observe in our gramicidin recordings.

\section{Role of ChCs in integrating Layer 1 inputs}

An unexpected result from our morphological analysis is the considerable bias in the location of $\mathrm{ChC}$ dendrites, which are largely confined to Layer 1 . The majority of previously published reconstructions of L2/3 ChCs have been located further from the L1 border (Somogyi et al., 1982; Zhu et al., 2004; Gonzalez-Burgos et al., 2005; Xu and Callaway, 2009), although one study showing ChCs situated at the top of $\mathrm{L} 2 / 3$ also appeared to demonstrate a preference for Layer 1 dendrites (Kawaguchi, 1995). We show here that despite their similar laminar position, basket cells do not display the same preference, suggesting different sources of afferent input for these two cell classes.

Layer 1 contains dense axonal projections emanating both from higher cortical areas and nonspecific thalamic nuclei (Lorente de Nó, 1949; Rockland and Pandya, 1979; Cauller et al., 1998; Douglas and Martin, 2007; Rubio-Garrido et al., 2009). Coarse-scale axodendritic overlap provides some insight into the sources of afferent input, but whether L2/3 ChCs sample equally from cortical and subcortical afferents is unknown. Interestingly, feedback, corticocortical projections from a region of extrastriate visual cortex to rat V1, did not contact PV+ dendrites of Layer 1 (Gonchar and Burkhalter, 2003). This is somewhat surprising in light of our finding regarding Layer 1 dendrites of Layer $2 / 3$ ChCs, and whether this reflects a general scarcity of PV + processes in Layer 1 or a direct avoidance by feedback inputs (and instead a preference for thalamic inputs) is unclear. 
Chandelier cell dendrites overlapped substantially with pyramidal neuron apical dendrites, where dendritic spikes can be initiated (Yuste et al., 1994; Schiller et al., 1997; Larkum et al., 2007). Dendritic spikes are facilitated by antidromic propagation of axonally initiated spikes and can themselves propagate to the soma to facilitate spike output from the AIS (Larkum et al., 1999). This cooperativity between two distinct neural pathways may therefore constitute a mechanism to associate bottom-up and top-down inputs. The induction of dendritic spikes will depend on the local excitatory-inhibitory balance. In this regard, two important interneuron types are Martinotti cells (Silberberg and Markram, 2007; Murayama et al., 2009), whose axons extend to Layer 1 from cell bodies in deeper layers, and neurogliaform cells (Wozny and Williams, 2011), which have dense local axons and whose cell bodies are routinely found in Layer 1. Neurogliaform cells may therefore provide a feedforward inhibition of the apical tuft, while Martinotti cells, due to their different sources of excitation, may provide tuft inhibition in response to local circuit rather than interareal input. In contrast, despite their dendritic arbor overlapping with pyramidal neuron apical tufts, chandelier cells will not directly affect dendritic spike initiation. Instead, a direct impact on axonal excitability is expected. Layer 2/3 chandelier cells could therefore provide a direct link between top-down, highly processed information arriving at Layer 1 and the axonal spike output of the pyramidal neuron. In a quiet circuit, a small depolarization provided by multiple ChCs may help axonal spike initiation, which can then interact with dendritic spikes to produce axonal spike bursts. On the other hand, in an active circuit, hyperpolarization or inhibition by ChCs, perhaps the dominant effect, will prevent axonal spike initiation and therefore prevent cooperativity between bottom-up and top-down inputs.

\section{Notes}

Supplemental material for this article is available at http://hdl.handle.net/ 10022/AC:P:11067. This material has not been peer reviewed.

\section{References}

Alger BE, Nicoll RA (1982) Pharmacological evidence for two kinds of GABA receptor on rat hippocampal pyramidal cells studied in vitro. J Physiol 328:125-141.

Azouz R, Gray CM (2008) Stimulus-selective spiking is driven by the relative timing of synchronous excitation and disinhibition in cat striate neurons in vivo. Eur J Neurosci 28:1286-1300.

Balena T, Woodin MA (2008) Coincident pre- and postsynaptic activity downregulates NKCC1 to hyperpolarize $\mathrm{E}(\mathrm{Cl})$ during development. Eur J Neurosci 27:2402-2412.

Beierlein M, Gibson JR, Connors BW (2000) A network of electrically coupled interneurons drives synchronized inhibition in neocortex. Nat Neurosci 3:904-910.

Ben-Ari Y (2002) Excitatory actions of GABA during development: the nature of the nurture. Nat Rev Neurosci 3:728-739.

Brumback AC, Staley KJ (2008) Thermodynamic regulation of NKCC1mediated $\mathrm{Cl}$ - cotransport underlies plasticity of $\mathrm{GABA}(\mathrm{A})$ signaling in neonatal neurons. J Neurosci 28:1301-1312.

Buhl EH, Halasy K, Somogyi P (1994) Diverse sources of hippocampal unitary inhibitory postsynaptic potentials and the number of synaptic release sites. Nature 368:823-828.

Cattell RB (1966) The scree test for number of factors. Multivariate Behav Res 1:245-276.

Cauller LJ, Clancy B, Connors BW (1998) Backward cortical projections to primary somatosensory cortex in rats extend long horizontal axons in layer I. J Comp Neurol 390:297-310.

Chattopadhyaya B, Di Cristo G, Higashiyama H, Knott GW, Kuhlman SJ, Welker E, Huang ZJ (2004) Experience and activity-dependent maturation of perisomatic GABAergic innervation in primary visual cortex during a postnatal critical period. J Neurosci 24:9598-9611.
Chavas J, Marty A (2003) Coexistence of excitatory and inhibitory GABA synapses in the cerebellar interneuron network. J Neurosci 23:2019-2031.

Choi HJ, Lee CJ, Schroeder A, Kim YS, Jung SH, Kim JS, Kim do Y, Son EJ, Han HC, Hong SK, Colwell CS, Kim YI (2008) Excitatory actions of GABA in the suprachiasmatic nucleus. J Neurosci 28:5450-5459.

Cohen I, Navarro V, Clemenceau S, Baulac M, Miles R (2002) On the origin of interictal activity in human temporal lobe epilepsy in vitro. Science 298:1418-1421.

Constantinople CM, Bruno RM (2011) Effects and mechanisms of wakefulness on local cortical networks. Neuron 69:1061-1068.

Crochet S, Petersen CC (2006) Correlating whisker behavior with membrane potential in barrel cortex of awake mice. Nat Neurosci 9:608-610.

Crochet S, Poulet JF, Kremer Y, Petersen CC (2011) Synaptic mechanisms underlying sparse coding of active touch. Neuron 69:1160-1175.

DeFelipe J, Hendry SH, Jones EG, Schmechel D (1985) Variability in the terminations of GABAergic chandelier cell axons on initial segments of pyramidal cell axons in the monkey sensory-motor cortex. J Comp Neurol 231:364-384

Douglas RJ, Martin KA (2007) Mapping the matrix: the ways of neocortex. Neuron 56:226-238.

Fairen A, Valverde F (1980) A specialized type of neuron in the visual cortex of cat: a Golgi and electron microscope study of chandelier cells. J Comp Neurol 194:761-779.

Fiumelli H, Cancedda L, Poo MM (2005) Modulation of GABAergic transmission by activity via postsynaptic $\mathrm{Ca} 2+$-dependent regulation of KCC2 function. Neuron 48:773-786.

Gentet LJ, Avermann M, Matyas F, Staiger JF, Petersen CC (2010) Membrane potential dynamics of GABAergic neurons in the barrel cortex of behaving mice. Neuron 65:422-435.

Glickfeld LL, Roberts JD, Somogyi P, Scanziani M (2009) Interneurons hyperpolarize pyramidal cells along their entire somatodendritic axis. Nat Neurosci 12:21-23.

Gonchar Y, Burkhalter A (2003) Distinct GABAergic targets of feedforward and feedback connections between lower and higher areas of rat visual cortex. J Neurosci 23:10904-10912.

Gonzalez-Burgos G, Krimer LS, Povysheva NV, Barrionuevo G, Lewis DA (2005) Functional properties of fast spiking interneurons and their synaptic connections with pyramidal cells in primate dorsolateral prefrontal cortex. J Neurophysiol 93:942-953.

Gulledge AT, Stuart GJ (2003) Excitatory actions of GABA in the cortex. Neuron 37:299-309.

Hestrin S, Galarreta M (2005) Electrical synapses define networks of neocortical GABAergic neurons. Trends Neurosci 28:304-309.

Howard A, Tamas G, Soltesz I (2005) Lighting the chandelier: new vistas for axo-axonic cells. Trends Neurosci 28:310-316.

Inda MC, Defelipe J, Munoz A (2009) Morphology and distribution of chandelier cell axon terminals in the mouse cerebral cortex and claustroamygdaloid complex. Cereb Cortex 19:41-54.

Jones EG (1975) Varieties and distribution of non-pyramidal cells in the somatic sensory cortex of the squirrel monkey. J Comp Neurol 160:205-267.

Kawaguchi Y (1995) Physiological subgroups of nonpyramidal cells with specific morphological characteristics in layer II/III of rat frontal cortex. J Neurosci 15:2638-2655.

Khirug S, Yamada J, Afzalov R, Voipio J, Khiroug L, Kaila K (2008) GABAergic depolarization of the axon initial segment in cortical principal neurons is caused by the Na-K-2Cl cotransporter NKCC1. J Neurosci 28:4635-4639.

Kim Y, Trussell LO (2007) Ion channels generating complex spikes in cartwheel cells of the dorsal cochlear nucleus. J Neurophysiol 97:1705-1725.

Larkum ME, Zhu JJ, Sakmann B (1999) A new cellular mechanism for coupling inputs arriving at different cortical layers. Nature 398:338-341.

Larkum ME, Waters J, Sakmann B, Helmchen F (2007) Dendritic spikes in apical dendrites of neocortical layer $2 / 3$ pyramidal neurons. J Neurosci 27:8999-9008.

Lorente de Nó R (1949) Cerebral cortex: architecture, intracortical connections, motor projections. In: Physiology of the nervous system (Fulton JF, ed), pp 228-330. New York: Oxford UP.

Molnar G, Olah S, Komlosi G, Fule M, Szabadics J, Varga C, Barzo P, Tamas G (2008) Complex events initiated by individual spikes in the human cerebral cortex. PLoS Biol 6:e222.

Murayama M, Perez-Garci E, Nevian T, Bock T, Senn W, Larkum ME (2009) 
Dendritic encoding of sensory stimuli controlled by deep cortical interneurons. Nature 457:1137-1141.

Poulet JF, Petersen CC (2008) Internal brain state regulates membrane potential synchrony in barrel cortex of behaving mice. Nature 454:881-885.

Rivera C, Voipio J, Payne JA, Ruusuvuori E, Lahtinen H, Lamsa K, Pirvola U, Saarma M, Kaila K (1999) The K+/Cl- co-transporter KCC2 renders GABA hyperpolarizing during neuronal maturation. Nature 397:251-255.

Rockland KS, Pandya DN (1979) Laminar origins and terminations of cortical connections of the occipital lobe in the rhesus monkey. Brain Res 179:3-20.

Romo-Parra H, Trevino M, Heinemann U, Gutierrez R (2008) GABA actions in hippocampal area CA3 during postnatal development: differential shift from depolarizing to hyperpolarizing in somatic and dendritic compartments. J Neurophysiol 99:1523-1534.

Rousseeuw PJ (1987) Silhouettes: a graphical aid to the interpretation and validation of cluster analysis. Comput Appl Math 20:53-65.

Rubio-Garrido P, Perez-de-Manzo F, Porrero C, Galazo MJ, Clasca F (2009) Thalamic input to distal apical dendrites in neocortical layer 1 is massive and highly convergent. Cereb Cortex 19:2380-2395.

Schiller J, Schiller Y, Stuart G, Sakmann B (1997) Calcium action potentials restricted to distal apical dendrites of rat neocortical pyramidal neurons. J Physiol 505:605-616.

Silberberg G, Markram H (2007) Disynaptic inhibition between neocortical pyramidal cells mediated by Martinotti cells. Neuron 53:735-746.

Simon A, Oláh S, Molnár G, Szabadics J, Tamás (2005) Gap-junctional coupling between neurogliaform cells and various interneuron types in the neocortex. J Neurosci 25:6278-6285.

Somogyi P (1977) A specific "axo-axonal" interneuron in the visual cortex of the rat. Brain Res 136:345-350.

Somogyi P, Freund TF, Cowey A (1982) The axo-axonic interneuron in the cerebral cortex of the rat, cat and monkey. Neuroscience 7:2577-2607.

Staley KJ, Soldo BL, Proctor WR (1995) Ionic mechanisms of neuronal excitation by inhibitory GABAA receptors. Science 269:977-981.

Steriade M, Contreras D, Curro Dossi R, Nunez A (1993) The slow $(<1 \mathrm{~Hz})$ oscillation in reticular thalamic and thalamocortical neurons: scenario of sleep rhythm generation in interacting thalamic and neocortical networks. J Neurosci 13:3284-3299.

Szabadics J, Varga C, Molnar G, Olah S, Barzo P, Tamas G (2006) Excitatory effect of GABAergic axo-axonic cells in cortical microcircuits. Science 311:233-235.

Szentagothai J (1975) The "module-concept" in cerebral cortex architecture. Brain Res 95:475-496.

Tamas G, Szabadics J (2004) Summation of unitary IPSPs elicited by identified axo-axonic interneurons. Cereb Cortex 14:823-826.

Viitanen T, Ruusuvuori E, Kaila K, Voipio J (2010) The K+-Cl cotransporter KCC2 promotes GABAergic excitation in the mature rat hippocampus. J Physiol 588:1527-1540.

Wagner S, Castel M, Gainer H, Yarom Y (1997) GABA in the mammalian suprachiasmatic nucleus and its role in diurnal rhythmicity. Nature 387:598-603.

Woodin MA, Ganguly K, Poo MM (2003) Coincident pre- and postsynaptic activity modifies GABAergic synapses by postsynaptic changes in $\mathrm{Cl}-$ transporter activity. Neuron 39:807-820.

Woodruff AR, Monyer H, Sah P (2006) GABAergic excitation in the basolateral amygdala. J Neurosci 26:11881-11887.

Woodruff A, Xu Q, Anderson SA, Yuste R (2009) Depolarizing effect of neocortical chandelier neurons. Front Neural Circuits 3:15.

Wozny C, Williams SR (2011) Specificity of synaptic connectivity between layer 1 inhibitory interneurons and layer $2 / 3$ pyramidal neurons in the rat neocortex. Cereb Cortex 21:1818-1826.

Xu X, Callaway EM (2009) Laminar specificity of functional input to distinct types of inhibitory cortical neurons. J Neurosci 29:70-85.

Yamada J, Okabe A, Toyoda H, Kilb W, Luhmann HJ, Fukuda A (2004) Cluptake promoting depolarizing GABA actions in immature rat neocortical neurones is mediated by NKCC1. J Physiol 557:829-841.

Yuste R, Gutnick MJ, Saar D, Delaney KD, Tank DW (1994) Calcium accumulations in dendrites from neocortical neurons: an apical band and evidence for functional compartments Neuron 13:23-43.

Zhu Y, Stornetta RL, Zhu JJ (2004) Chandelier cells control excessive cortical excitation: characteristics of whisker-evoked synaptic responses of layer $2 / 3$ nonpyramidal and pyramidal neurons. J Neurosci 24:5101-5108.

Zsiros V, Maccaferri G (2005) Electrical coupling between interneurons with different excitable properties in the stratum lacunosummoleculare of the juvenile CA1 rat hippocampus. J Neurosci 25:86868695. 